\title{
آثار تأجيل الدعوى الجزائية في ضوء التشريعات الجزائية الإجرائية العببية
}

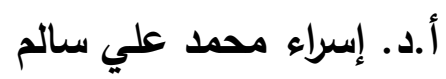

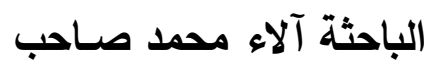

كلية القانون/ جامعة بابل

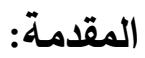

تتعدد الآثار التي يمكن أن تترتب على تأجيل الدعوى الجزائية منها آثار إجرائية تتعلق بنظر الدعوى

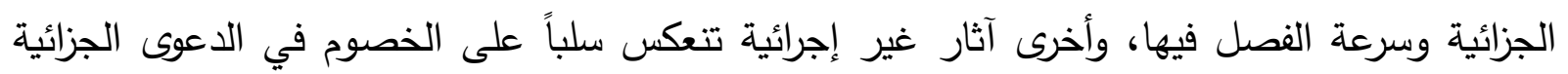

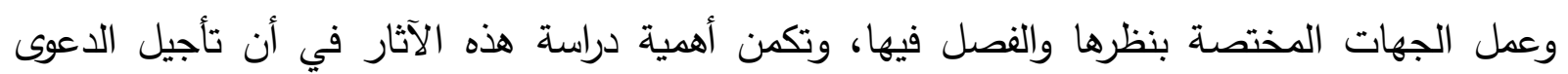

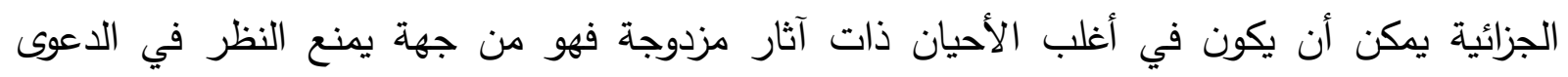

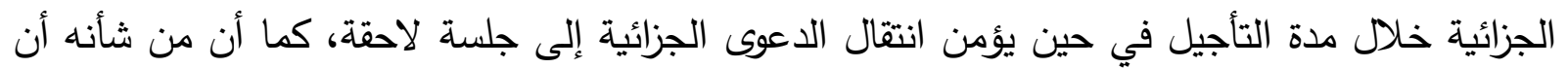

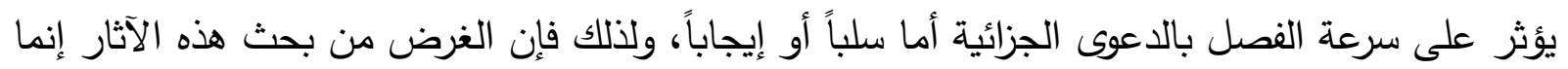

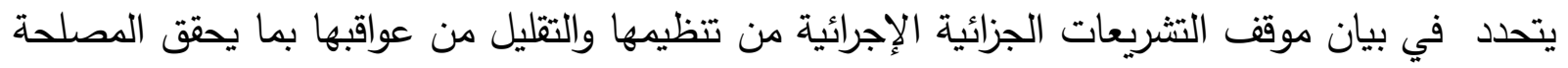
العامة والخاصة في ذات الوقت وخلق حالة من التوازن بين ما تعارض منها.

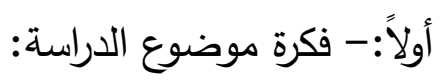

نظم المشرع آلية سير الدعوى الجزائية ومنح للجهة القضائية الدختصة صلاحية تأجيل الدعوى الجزائية

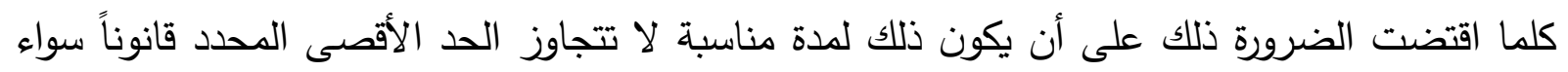

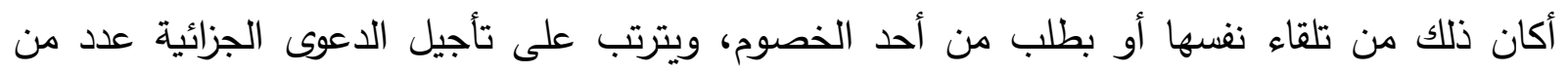

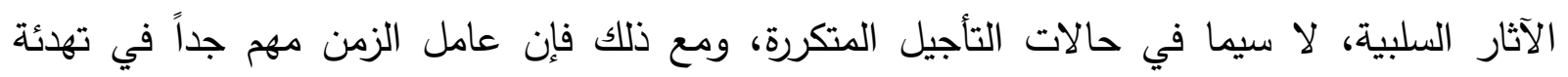

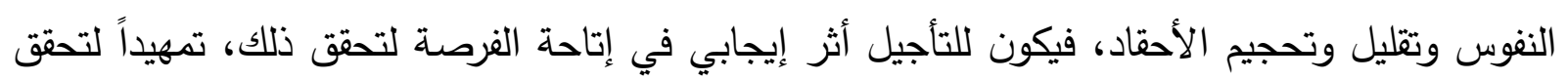

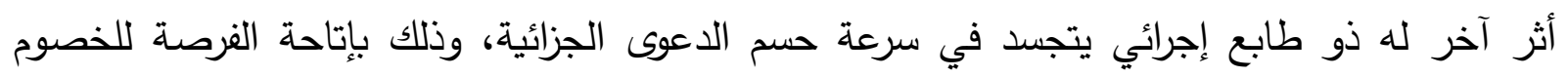


للتوصل إلى حصول الصلح بينهم وإنقضاء الدعوى الجزائية القائمة بينهم بما يكفل حسن سير العدالة في إطار الدعوى الجزائية وحفظوقت العدالة من الهدر •

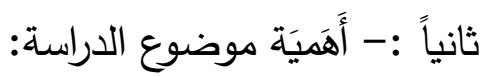
تظهر أهمية البحث في موضوع آثار تأجيل الدعوى الجزائية في أن هذا الموضوع لم يحظَ بالعناية الكافية

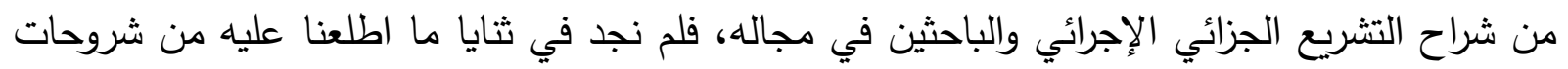

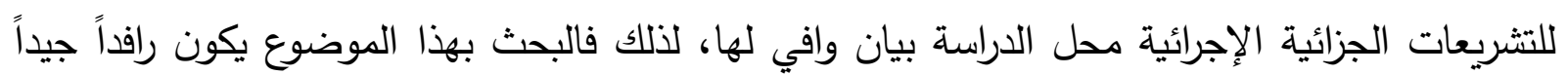
للمكتبة القانونيــة. ثالثاً:-- إثكالية الدراسة: تتمثل إثكالية الدراسة في التعرف على أهم الآثار التي يمكن أن تترتب على تأجيل الدعوى الجزائية ومدى فعالية الحلول التي نظمها المشرع العراقي • رابعاً : منهجية الدراسة: إن دراسة موضوع آثار تأجيل الدعوى الجزائية ستكون - بعونه تعالى - على وفق المنهج التحليلي المقارن، ويقصد بالمنهج التحليلي عدم الوقوف عند ظاهر النصوص وإنما تحليلها للوصول إلى غاية

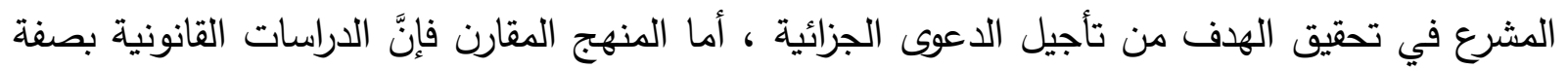

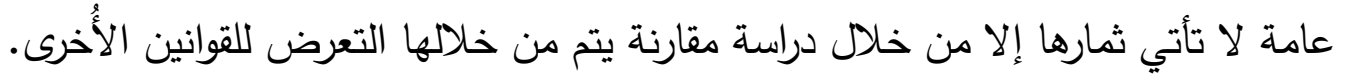
خامساً:- هيكلية الدراسة: سنتناول دراسة (آثار تأجيل الدعوى الجزائية - دراسة مقارنة) في مبحثين يسبقها مقدمة ، سنخصص

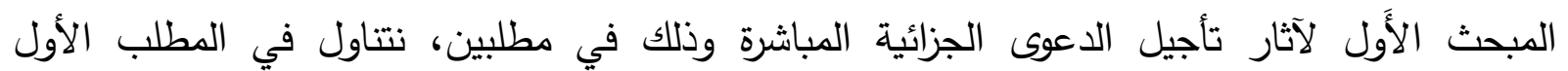

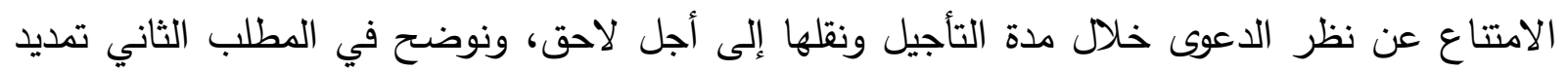
توقيف المتهم الموقوف، وبالنسبة للمبحث الثاني فنستعرض فيه آثار تأجيل الدعوى الجزائية غير المباشرة من خلال مطلبين، سنتناول في المطلب الأَول الأثر السلبي لتأجيل الدعوى الجزائية على سرعة إجراءاتها 
، ونغرد المطلب الثاني لبيان الأثر الإيجابي لتأجيل الدعوى الجزائية على سرعة إجراءاتها ، وسنختم البحث بأهم ما سنتوصل إليه من استتتاجات ومقترحات ...سائلين المولى عز وجل التوفيق والسداد. المبحث الأول: آثار تأجيل الدعوى الجزائية المباشرة:

يترتب على تأجيل الدعوى الجزائية بوصفه إجراءً قضائياً تتظيمياً عدد من الآثار الإجرائية المباشرة التي

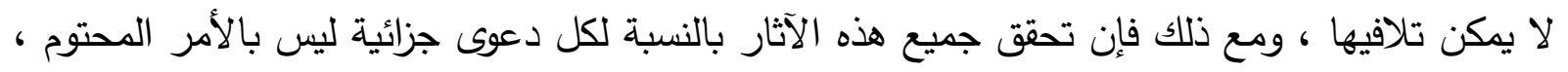
فمن آثار التأجيل المباشرة ما يتحقق في كل دعوى جزائية وهي ترد في الحال على سير الدعوى الجزائية

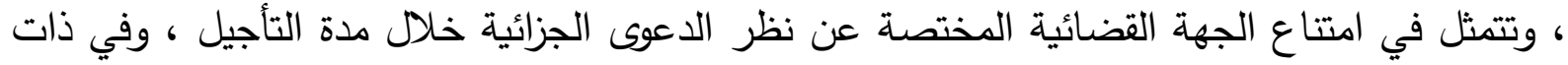

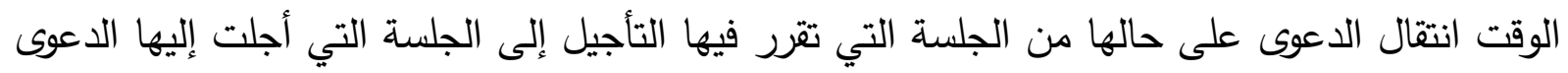

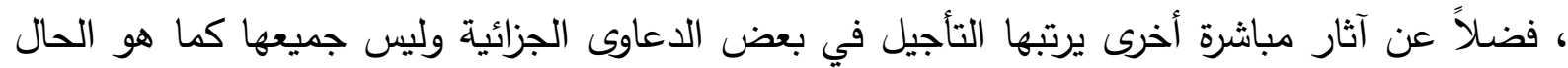

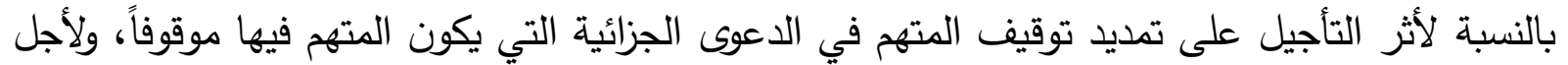
التعرف على هذه الآثار المباشرة سيتم تتاولها في فرعين وعلى النحو الآتي:

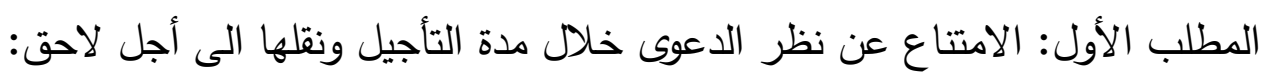
يتخذ تأجيل الدعوى الجزائية طابع التأقيت ، فهو إجراء مؤقت ينتهي بانقضاء مداء مداء معينـة ، ومن الآثار

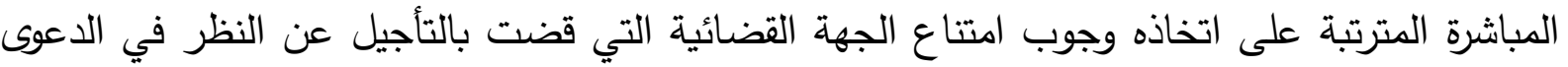

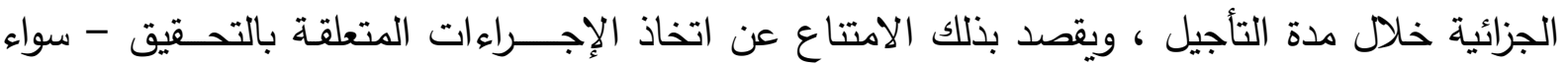

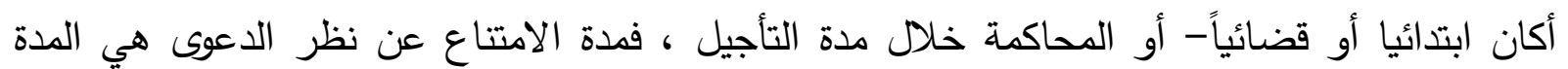

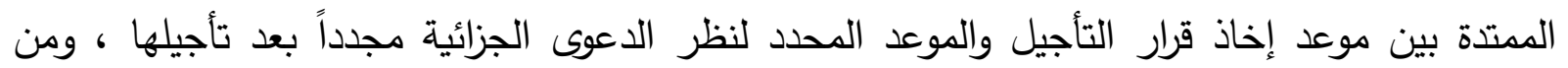
الجدير بالذكر أن تحديد الموعد الأخير الذي تتحدد في ضوئه مدة الامتتاع عن نظر الدعوى الجزائية

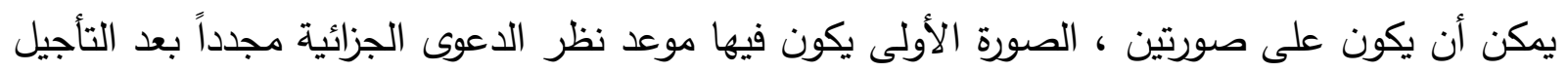
محدد بتأريخ معين ، ويكون ذلك بقيام محكمة الموضوع أثناء نظرها لإحدى الدعاوى الجزائية بتحديد

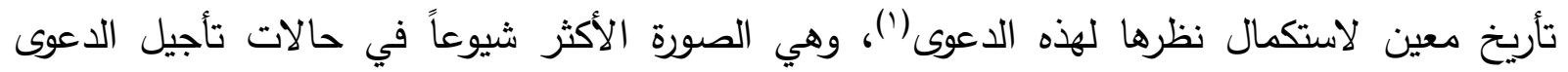


الجزائية ، وفي هذه الصورة تكون مدة التأجيل معلومة ، أما الصورة الثانية فيتحدد فيها موعد نظر الدعوى

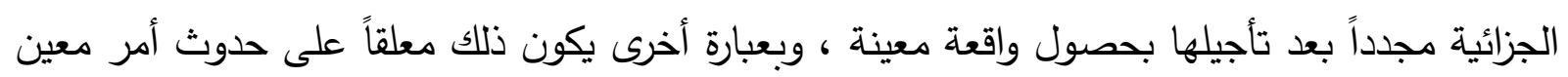

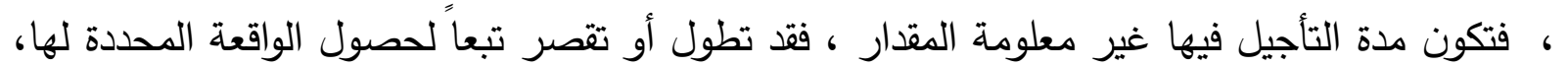

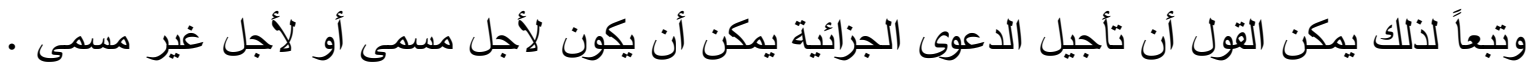
وفي الحقيقة تتفق التشريعات الجزائية الإجرائية محل الدراسة المقارنة في موقفها من اعتماد فكرة تأقيت إجراء تأجيل الدعوى الجزائية ، فبالنسبة للتشريع العراقي نجد أن المشرع قد بادر بكفالة فكرة التأقيت هذه التهاته

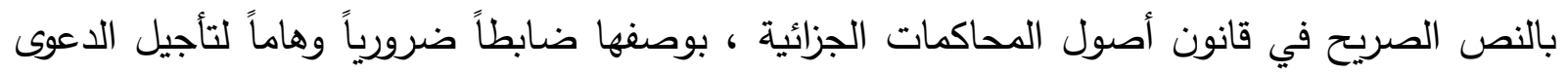
الجزائية تمليه ضرورة المحافظة على وقت الدعوى الجزائية بصفة خاصة ، وعدم إهدار وقت العدالة

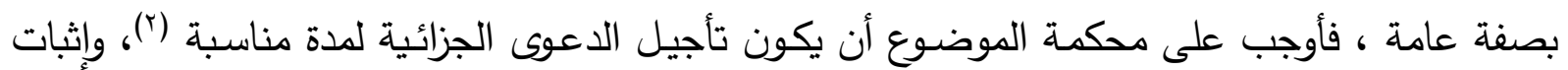

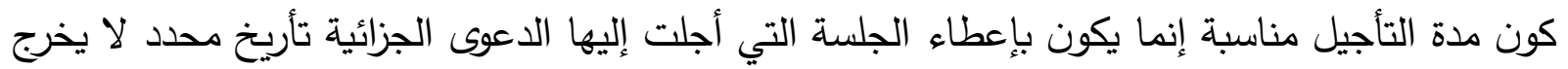

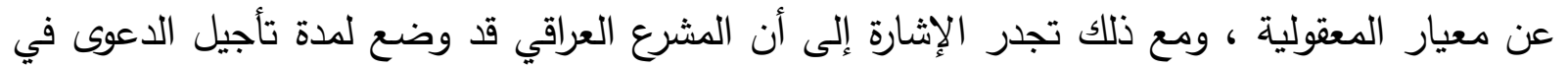

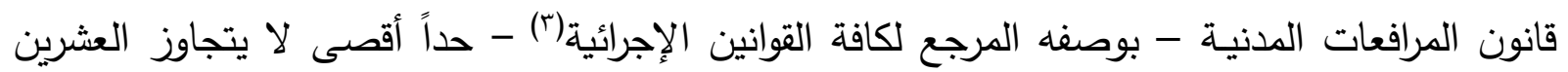
يوماً ، وذلك في الفقرة (ץ) من المادة (rT) فقد نصت على أن " ...لا يجوز أن تتجاوز مدة التأجيل عشرين يوماً إلا إذا اقتضت الضرورة ذلك..." ، ويتضح من النص أن الأصل هو عدم جواز تأجيل

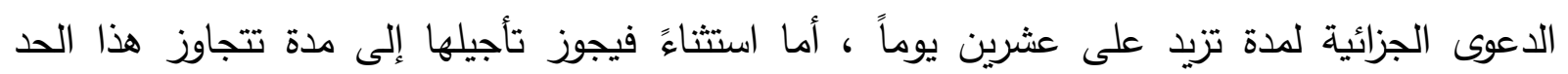

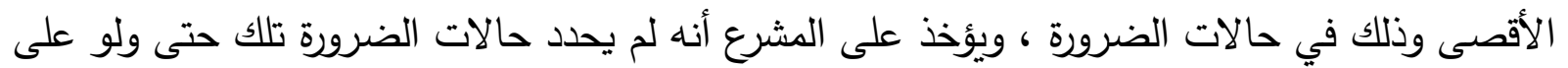

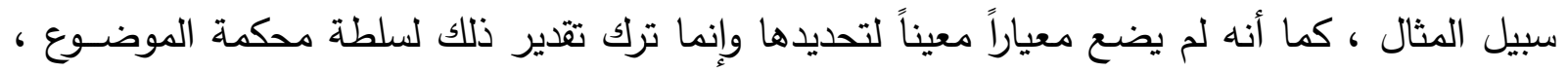
وهي لا تخضع في ذلك لرقابة جهة الطعن، ولا يخلو هذا الاستثناء من الخطورة إذ يمكن أن يكون تأجيل

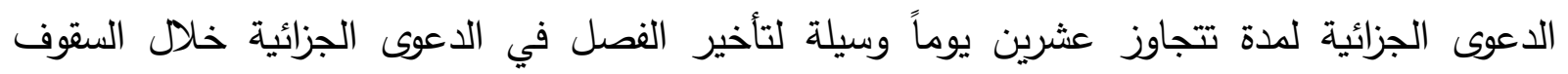
الزمنية المحددة لحسم الدعوى الجزائية ، لا سيما إذا لم يقتصر الأمر على تأجيلها لمرة واحدة فقط وإنما

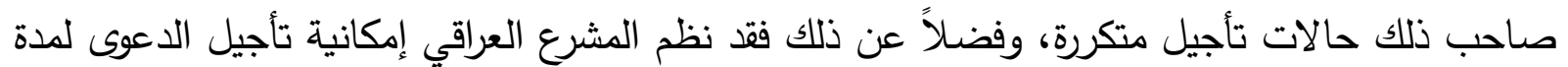


غير محددة بتأريخ معين ، وإنما جعل تحديد هذه المدة معلقاً على حصول واقعة معينة ، وتحديداً عودة

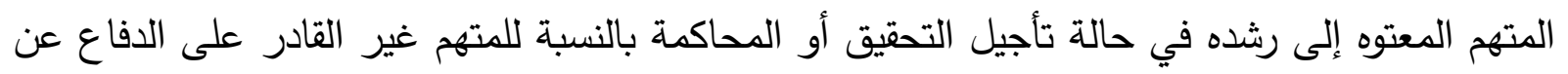
نفسه لثبوت إصابته بعاهة عقلية (؛)، وهو بذلك لم يخرج عما أقر به لإجراء التأجيل من طبيعة مؤقتة ،

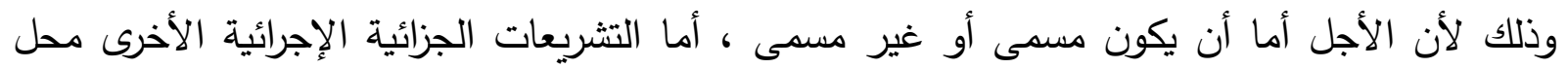

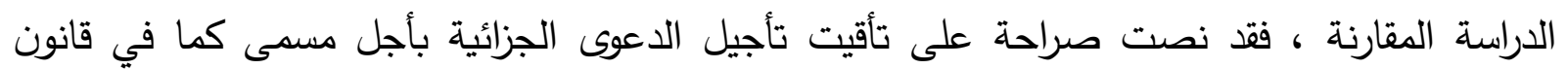

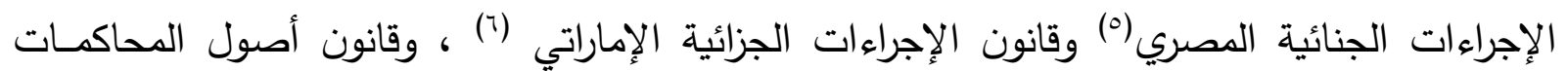

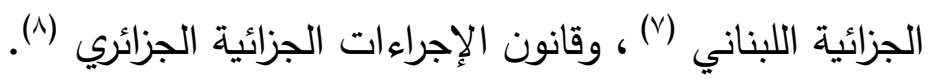
وتأسيساً على ما تقدم يختلف تحديد نطاق الامتتاع عن نظر الدعوى الجزائية خلال مدة تأجيل الدعوى ولاتئ

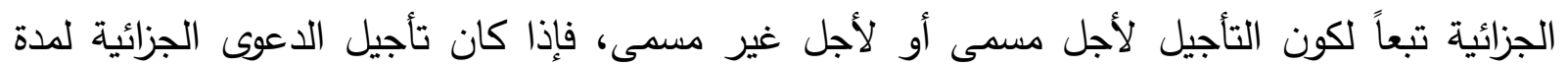

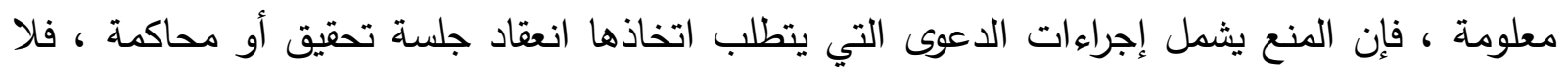

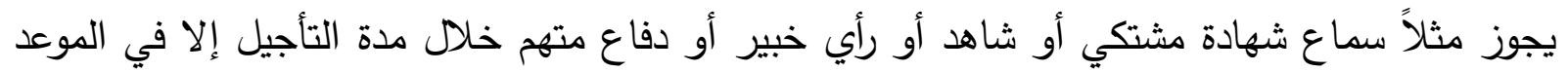

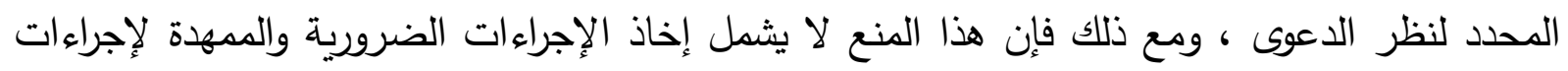

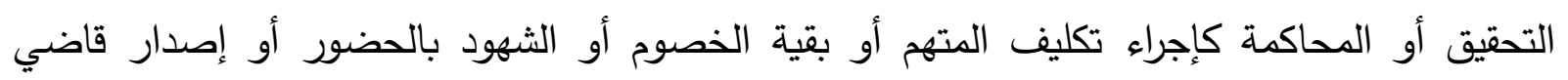

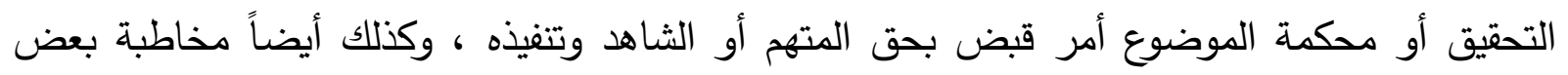
الجهات المختصة ذات العلاقة كدائرة الأدلة الجنائية أو الدوائر الرسمية الأخرى ، وذلك تمهيداً لما يتطلبه استكمال نظرها في الجلسة اللاحقة . أما إذا كان تأجيل الدعوى الجزائية لمدة غير معلومة الأجل فأن الواقع العملي استقر على أن الامتناع

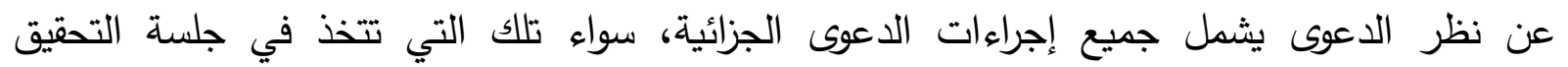

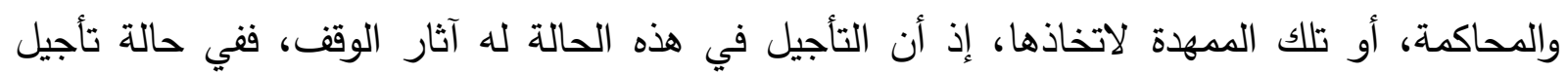

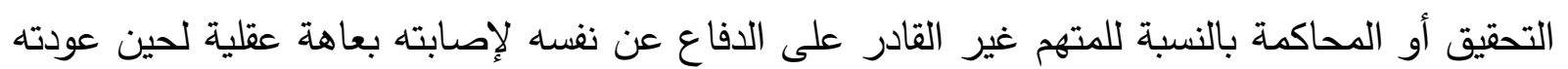
إلى رشده لا يتخذ أي إجراء في الدعوى الجزائية خلال مدة التأجيل لحين عودة المتهم إلى رشده. 
ومن الجدير بالذكر أن الامتتاع عن نظر الدعوى لا يرافقه وقف سير الدعوى الجزائية وإنما تكون الدعوى

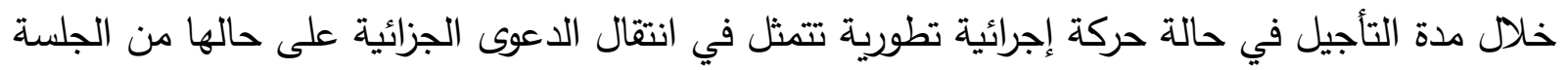

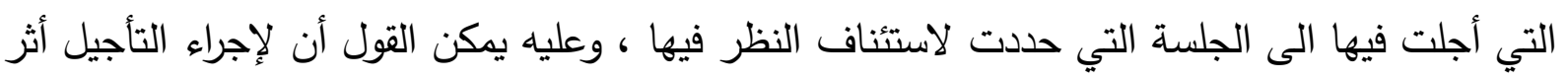
مزدوج فيما يتعلق بالدعوى الجزائية المؤجلة يتمثل في تعليق إجراءات الدعوى الجزائية خلال مدة التأجيل

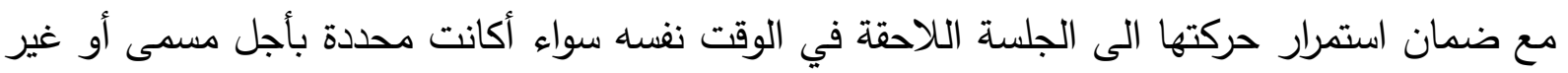

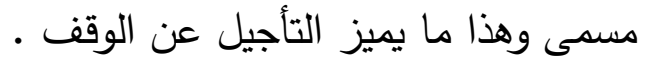

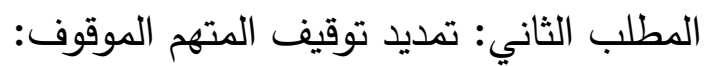

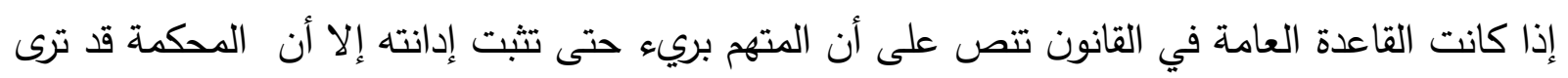
توقيف المتهم، و يراد به إجراء من اجراءات التحقيق الابتدائي ، وهو من أخطر تلك الاجراءات واكثرها

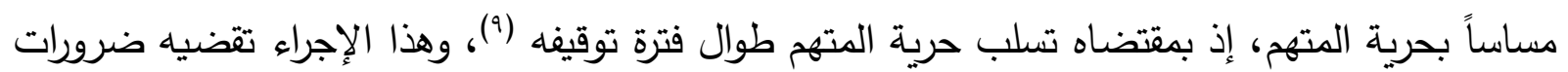

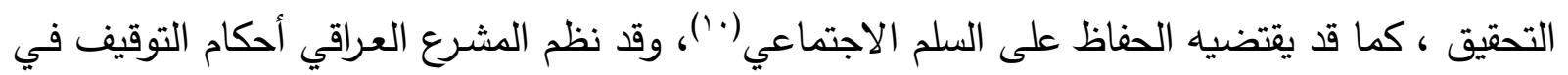

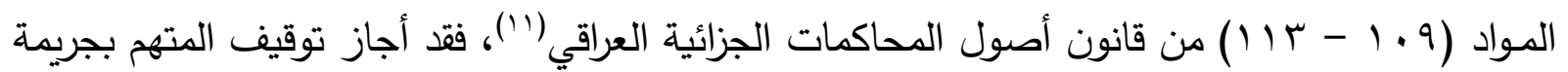
معاقب عليها بالحبس مدة تزيد على ثلاث سنوات أو بالسجن المؤقت أو المؤبد ، وذلك في الفقرة (أ) من

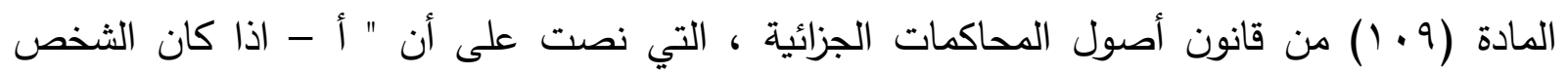
المقبوض عليه متهماً بجريمة معاقب عليها بالحبس مدة تزيد على ثلاث سنوات أو بالسجن المؤقت أو أو الون

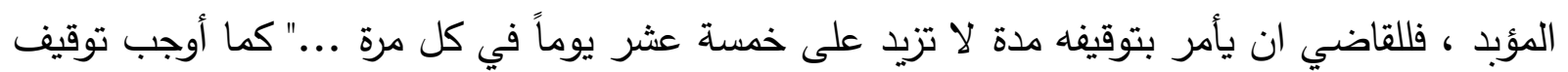

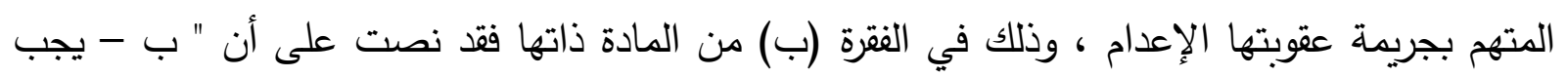

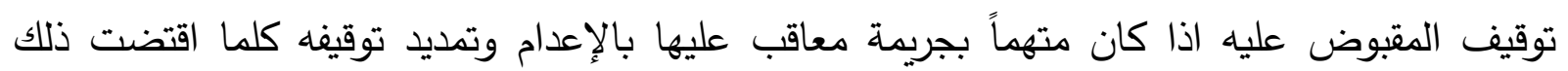

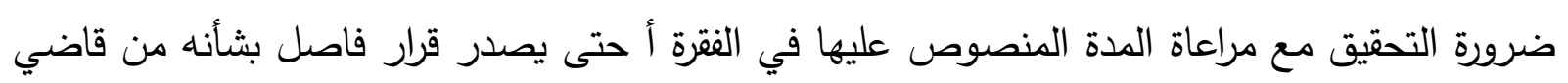

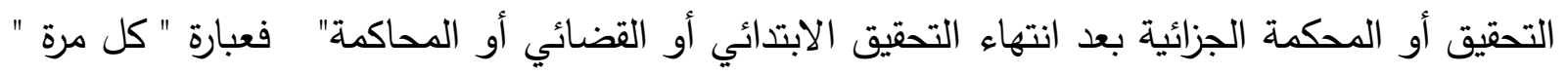
الواردة في الفقرة (أ) تثير ضمناً إلى إمكانية تمديد توقيف المتهم سواء في مرحلة التحقيق الابتدائي ، أو 
مرحلة المحاكمة لمدة لا تزيد على خمسة عشر يوماً ، أما الفقرة (ب) فقد أشارت إليه صراحةً بوصفه

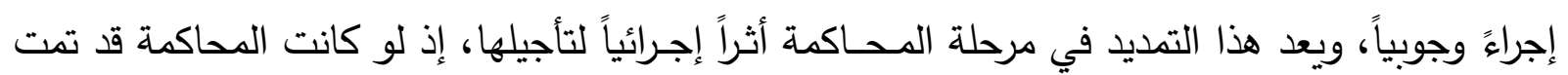

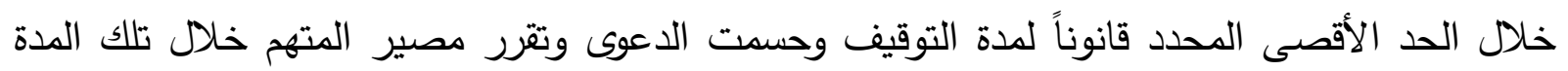
لانتقت الحاجة إلى تمديد توقيفه ،أما إذا قررت المحكمة تأجيل المحاكمة في الدعوى الجزائية ، فإن الأمر

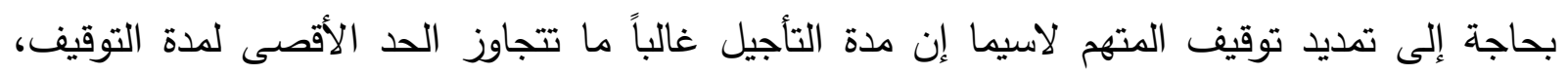

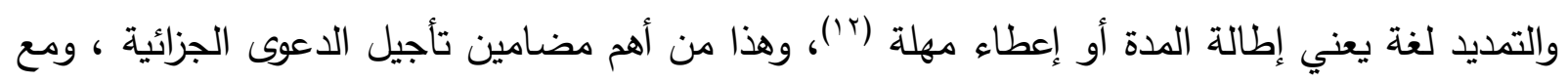
ذلك فقد وضع المشرع حد أقصى لتمديد مدة التوقيف لا يجوز تجاوزه وذلك في الفقرة (ج) من المادة

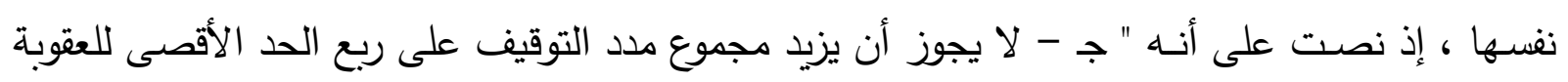

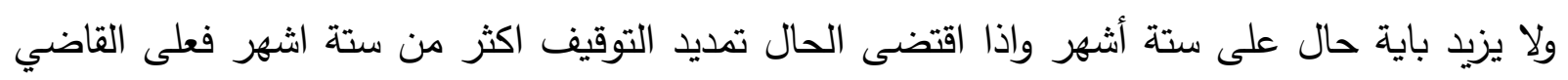

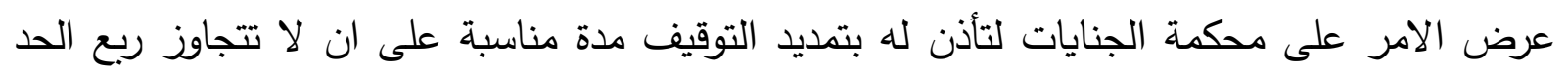
الاقصى للعقوبة ...."، ويمكن اعتبار تمديد التوقيف في مرحلة التحقيق الابتدائي أثراً مباشراً لتأجيل لأتيل

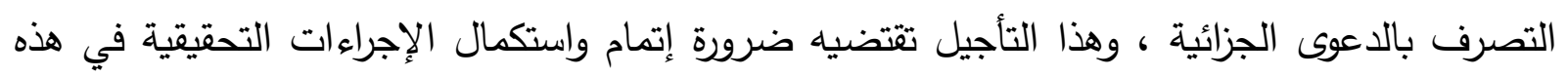

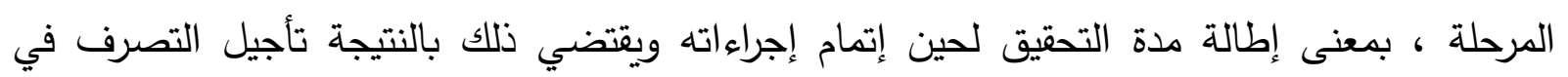

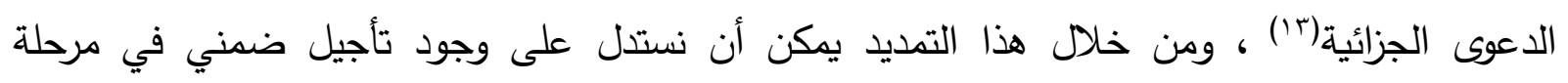

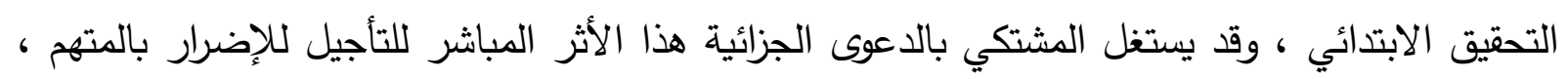

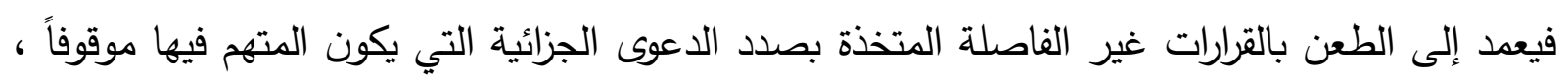
أو يطلب التحخل تمييزاً فيها ، أو أي إجراء آخر يؤدي إلى إرسال إضبارة الدعوى الجزائية إلى الجهة

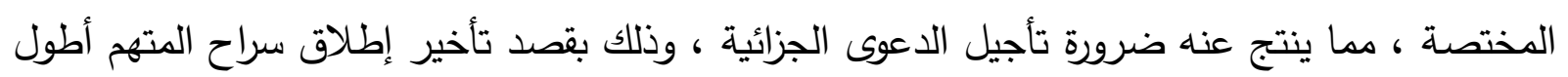

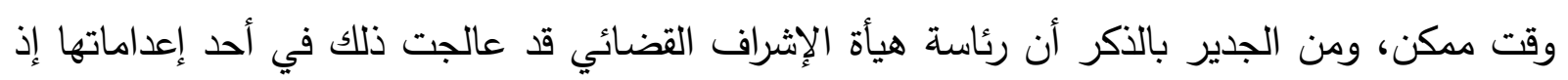

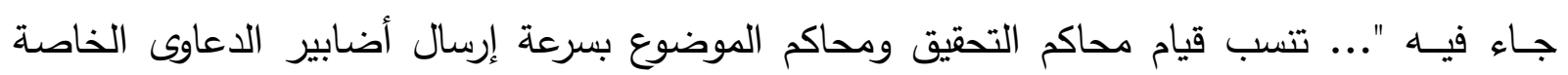
بالمتهمين الموقوفين إلى محكمة التمييز الاتحادية عند حصول أي طعن تمييزي يكون القصد من وراءه 
تأخير إطلاق سراح المتهم الموقوف وإبقائه موقوفاً أطول فترة ممكنة ويتولى رئيس محكمة الاستئناف

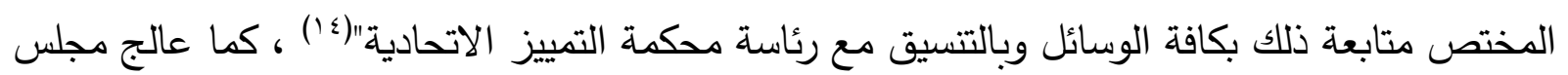
القضاء الأعلى ذلك في أحد إعداماته إذ تضمن "...الزام القاضي الذي يقدم إليه الطعن أن يقوم بإحالته الى المحكمة المختصة بصرف النظر عن العنوان الذي كتبه المميز في عريضته التمييزية وكذا الحال

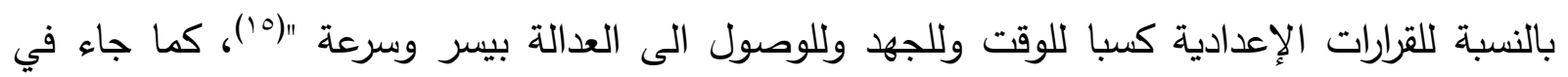
إعمام آخر له"...عند تكرار الطعن التمييزي بالقرارات الإعدادية فعلى المحكمة المختصة اتخاذ قراراها بعدم إرسال الدعوى والاكتفاء بإرسال لائحة الطعن على أن تلتزم محكمة الطعن بنظره خلال سبعة أيام

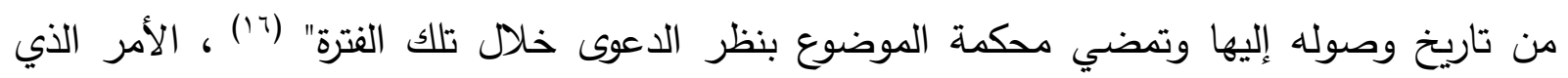

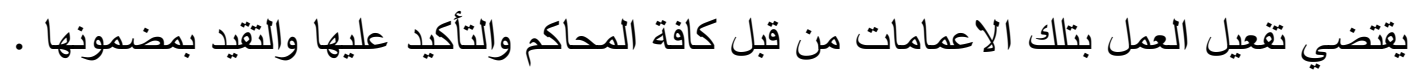
المبحث الثاني: آثار تأجيل الدعوى الجزائية غير المباشرة: إن تأجيل الدعوى الجزائية بوصفه إجراء يرتبط بعلاقة وثيقة بعامل الوقت في الدعوى الجزائية لذا يتسع نطاق آثاره ليشمل بصورة غير مباشرة الإطار العام لسرعة سير الدعوى الجزائية، والمدى الزمني

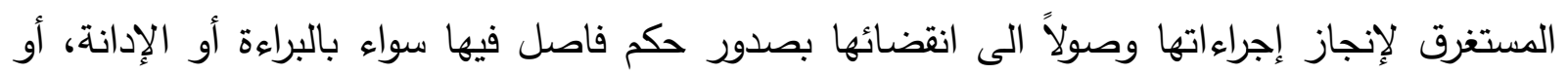
قبل ذلك لأي سبب من أسباب الانقضاء الأخرى ، وهذا الأثر يمكن أن يكون على صورتين متتاقضتين،

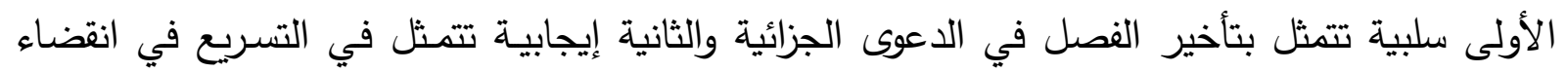
الدعوى الجزائية ، وهذا ما سيتم بيانه في مطلبين وعلى النحو الآتي: المطلب الأول: الأثر السلبي لتأجيل الدعوى الجزائية على سرعة إجراءاتها:

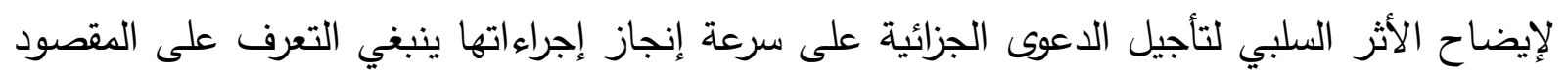

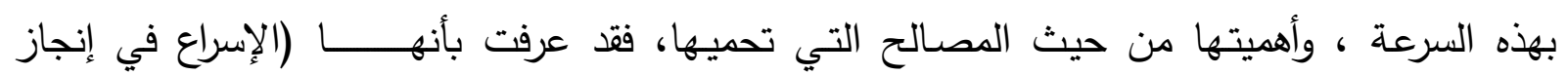
وإنهاء الإجراءات القضائية وفصل الدعوى الجزائية خلال مدة معقولة ومقبولة ، دون الإخلال بالضمانات المقرة لحق الدفاع)(V) ، ويتضح من تعريف أنها تؤكد على أن الأصل في الإجراءات الجزائية الإسراع 
في إنجازها وإنهاءها في أقرب وأقصر وقت ممكن ، واستثناءً من ذلك يجوز التأخير المبرر في إنجازها

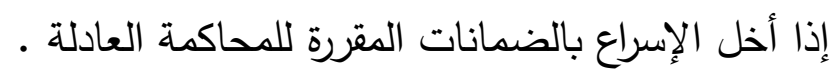

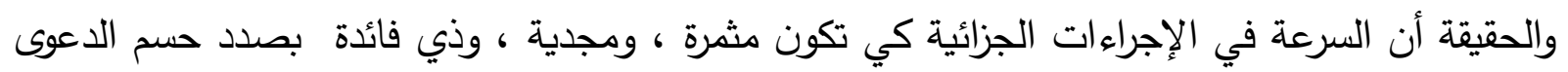

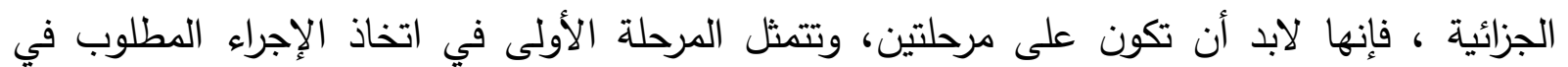

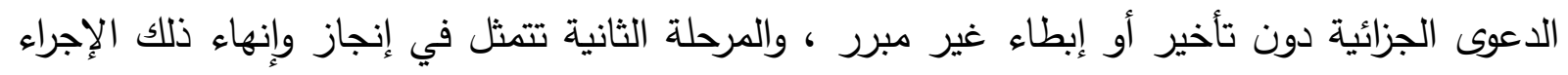
في أقصر وقت ممكن ، فلا تتصرف السرعة الى إنجازه وإنهائه فحسب وإنما تشمل أيضاً اتخاذه ، وعليه فإن السرعة في الإجراءات تعد مطلوبة ومهمة في كافة مراحل الدعوى الجزائية سواء مرحلة التحري وجمع إندان

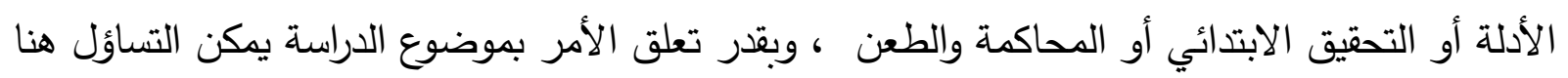
بصدد أثر تأجيل الدعوى الجزائية على سرعة اتخاذ الإجراءات الجزائية وإنجازها في مختلف مراحل الدعوى الجزائية ؟ والجواب على ذلك يقتضي إيضاح أثر التأجيل على سرعة إجراءات كل مرحلة من

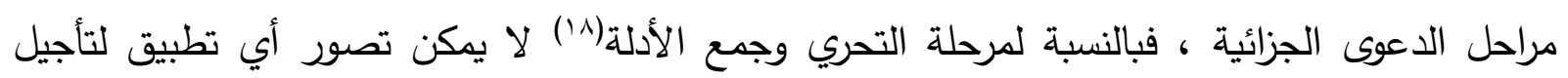

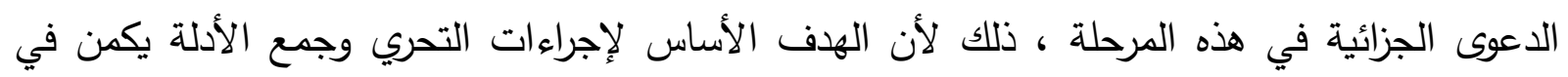

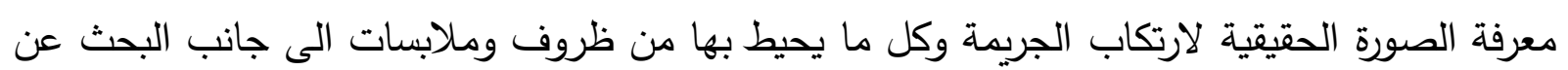
العوامل المختلفة في ارتكابها ، وكذلك ملاحقة مرتكبها وجمع القدر الممكن من الأدلة والمعلومات المتعلقة

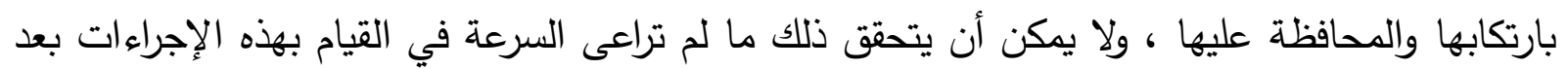

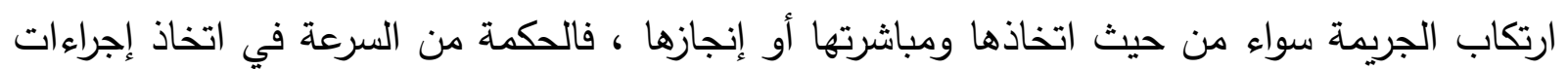
التحري وجمع الأدلة تكمن في أنه كلما مضى وقت على ارتكاب الجريمة كلما زاد احتمال اختفاء الأدلة

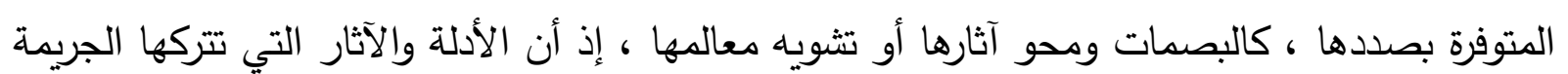

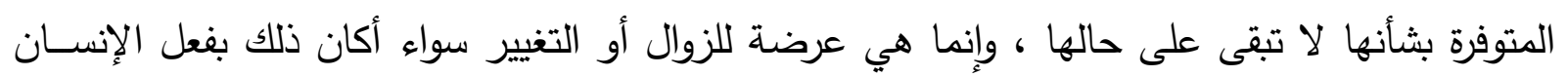

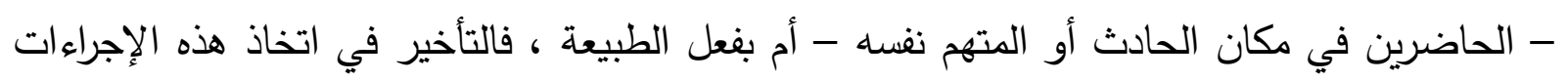

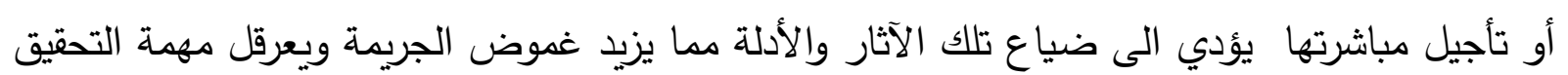


، والتأجيل في هذه الحالة يعد تسويفاً ومماطلة كونه تأجيل غير مبرر قانوناً، في حين الإسراع في مباشرة

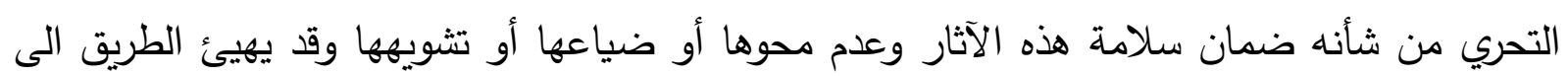

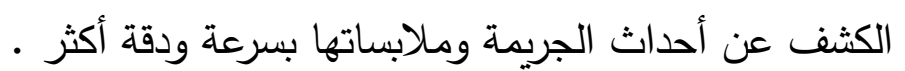
وجدير بالذكر أن السرعة لا تقتصر فقط على البدء بمباشرة إجراءات التحري وجمع الأدلة ، فالأداء المطلوب لإجراءات التحري وجمع الأدلة يجب أن يكون على نحو من السرعة كون المهمة لا تحتمل التأخير فيها أو تأجيلها ، ولذلك نجد المشرع العراقي قد صرح بضرورة مراعاة السرعة في القيام بإجراءات

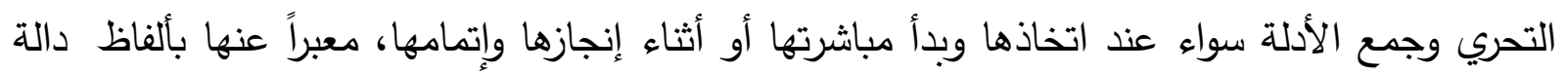
على معناها وهي "فوراً" أو "على الفور" أو "في الحال"، وذلك في نصوص قانون أصول أصول الهحاكمات

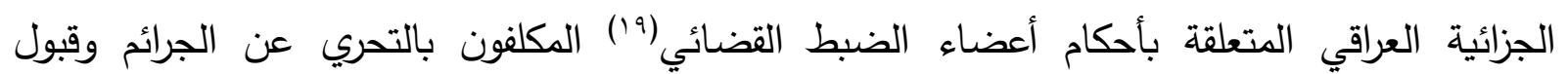
الإخباريات والثكاوى التي ترد اليهم بثأنها ، وتقديم المساعدة لقضاة التحقيق والمحققين وضباط الثرطة

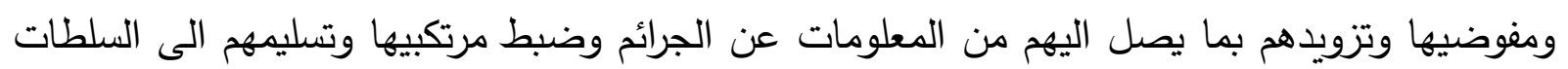

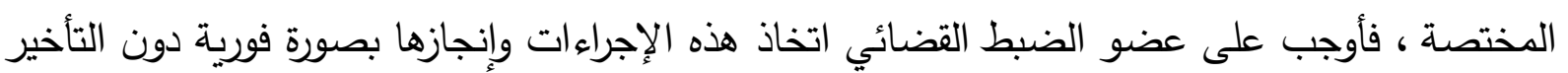

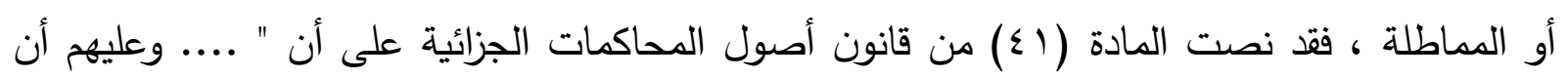
يثبتوا جميع الاجراءات التي يقومون بها في محاضر موقعة منهم ومن الحاضرين ، يبين فيها الوقت الذي واتي

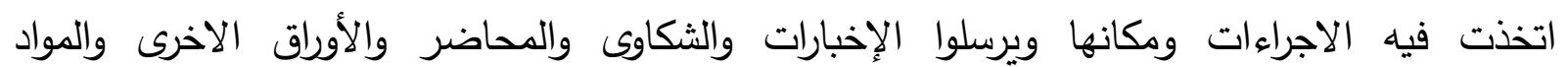

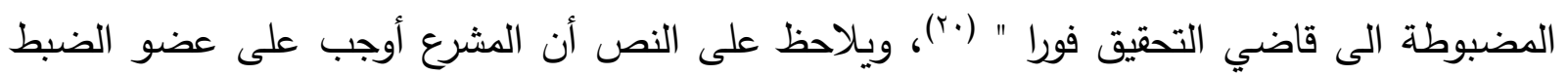

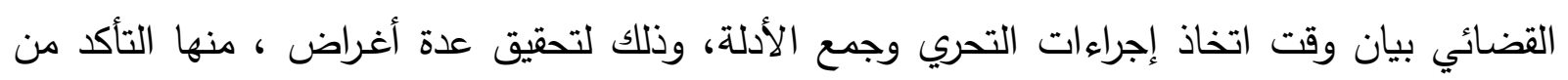
فوريتها وعدم التسويف والمماطلة في اتخاذها، ويعتمد ذلك بالدرجة الأولى على مدى اقتراب اتخاذ هذه التهائ الإجراءات لزمان وقوع الجريمة ، وما مضى من مدة بين وقوعها ومباشرة التحري بصددها ، فتأجيل اتخاذ التهات

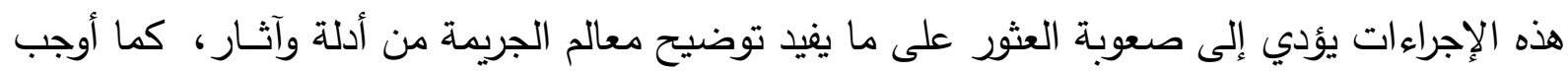
على عضو الضبط القضائي السرعة في إتمام هذه الإجراءات ، وذلك بإرسال كل ما توصل إليه بنتيجة 
التحري وجمع الأدلة الى قاضـي التحقيق على الفور ، كالثكاوي والإخبارات والمواد المضبوطة نظراً لما

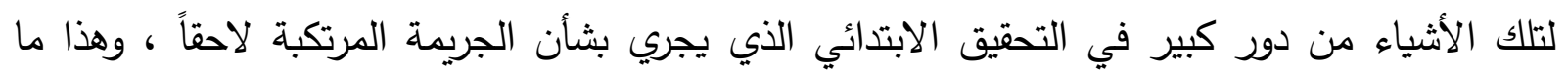

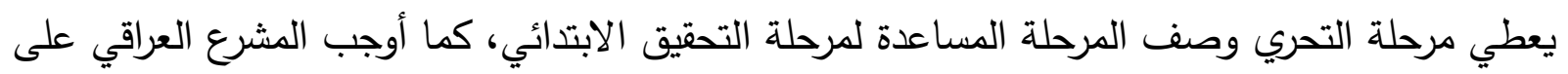

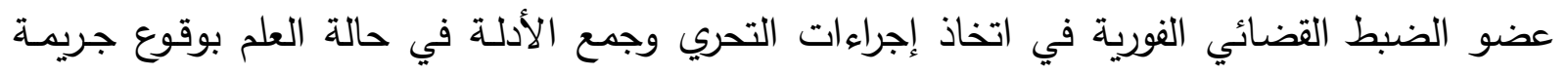

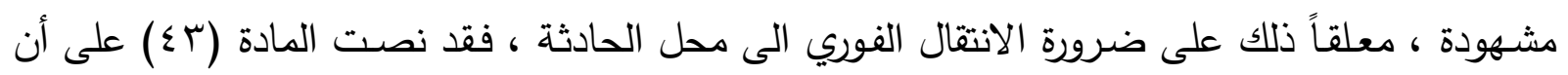

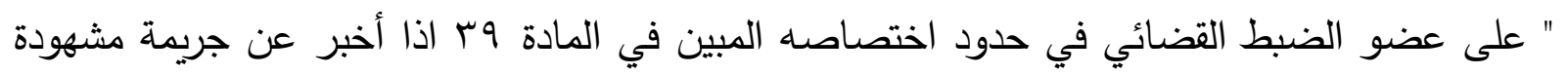

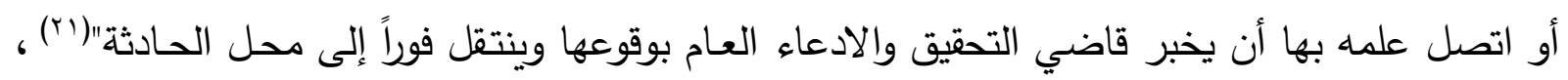
فيتضح من النص طبيعة التحرك المطلوب من عضو الضبط القضائي عندما يصل الى علمه وقوع جريمة مشهودة ، إذ يجب أن يتسم بالسرعة ، ويتحقق ذلك في سرعة إخبار قاضي التحقيق والادعاء

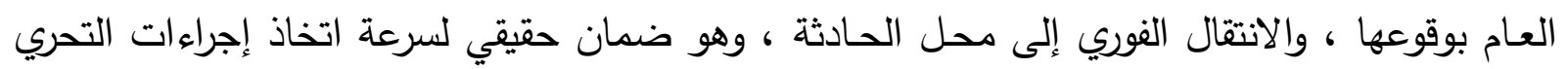
وجمع الأدلة في محل الحسادثة ، كتدوين إفادة المجنى عليه وسؤال المتهم عن التهمة المسندة اليه شفوياً ، وضبط الاسلحة ، وغير ذلك من الإجراءات ، فلا مجال لتأجيل اتخاذ أي منها ، كما نصت التهن المادة (

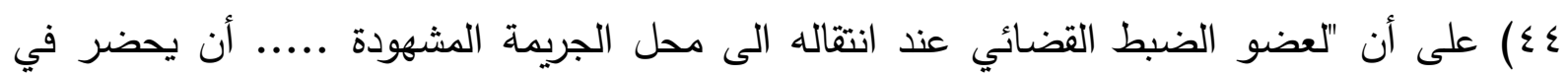

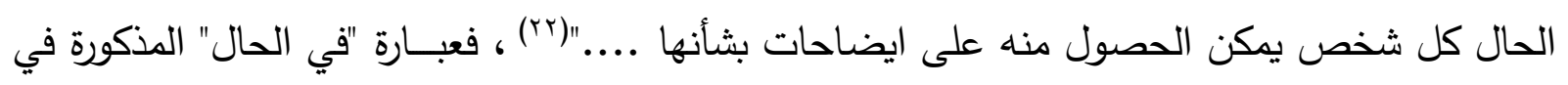

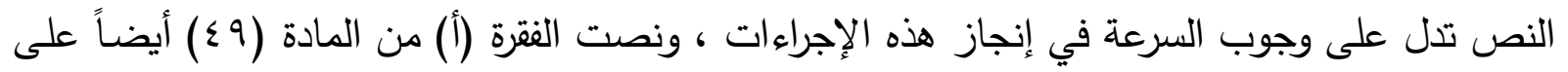
أن " أ- على اي مسؤول في مركز الشرطة عند وصول إخبار إليه بارتكاب جناية او جنحة ان يدون

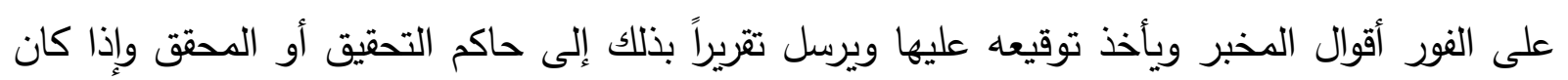
الإخبار واقعاً عن جناية او جنحة مشهودة فعليه ان يتخذ الاجراءات المبينة في المادة بـع "(rr) .

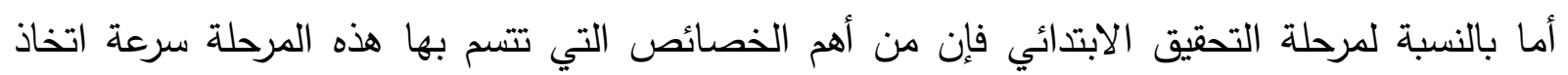
وإنجاز إجراءاتها، التي تستهف الكثف عن حقيقة الجريمة المرتكبة، ووقائعها، وكيفية ارتكابها، والتوصل إلى معرفة مرتكبها ، وبيان درجة مسؤوليته بوصفه فاعلاً أو شريكاً تمهيداً لإحالته إلى المحكمة ألى 
المختصة لينال جزاءه العادل (צr)، ويتم ذلك من خلال تمحيص مختلف الأدلة القائمة والمعلومات المتوفرة التي جمعت في مرحلة التحري وجمع الأدلة وتدقيقها وتقديرها، بغية التمهيد لإصدار القرار المناسب بشأن صلاحية عرض الدعوى الجزائية على المحكمة المختصة، وإحالة المتهم اليها إذا كانت الأدلة المتوفرة

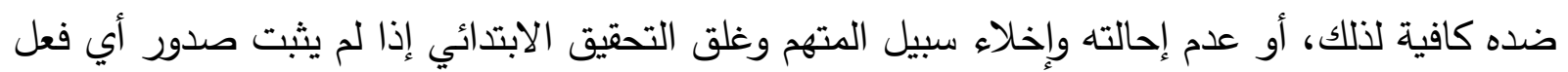

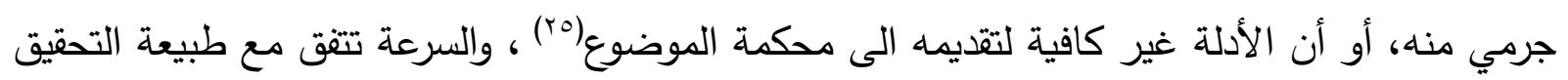
الابتدائي وأهدافه والغاية من تقريره ، فهي تحقق مصلحة المجتمع والمتهم في آن واحد إذ تساعد في حماية حق المجتمع بإنزال العقاب بالمجرم ، وتحقيق غرضه في الردع العام وذلك بضمان بلان محاكمته في

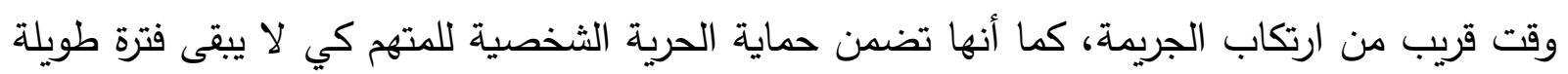
في مركز سلبي متمثل بالاتهام وانتظار مصير مجهول(זr)، أما إذا كان مذنباً فيما أتهم به ، فإن سرعة التهاه التحقيق تؤدي إلى التعجيل بتوقيع العقاب عليه ، وبذلك يستقر مركزه القانوني، بوصفه محكوم عليه يتم إيداعه في إحدى المؤسسات العقابية ويتلقى فيها معاملة قد تكون أفضل بكثير مما كان عليه أثناء التوقيف فضلاً عن تمتعه بعدد غير قليل من الحقوق كالزيارات وتلقي العلاج والخضوع لعملية الإصلاح

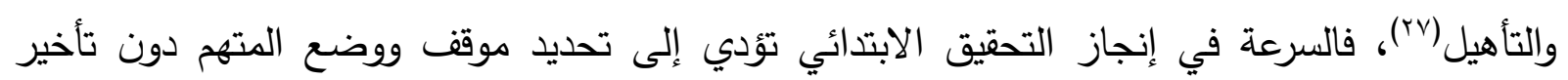
يلحق به ضرر يتعذر جبره (r^). والسرعة المقصودة في إجراءات التحقيق الابتدائي يجب أن لا تفسر تفسيراً ضيقاً بأن تستند إلى المعنى اللفظي للسرعة الذي ينصرف الى إنجاز المهمة خلال فترة زمنية قصيرة ، إذ إن من شأن السرعة المطلقة

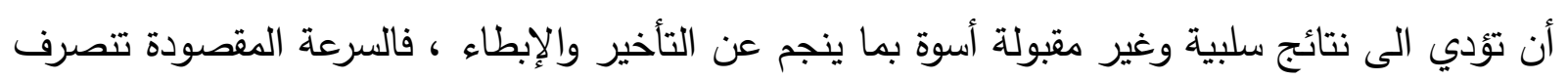

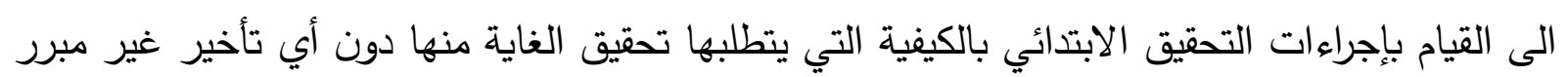

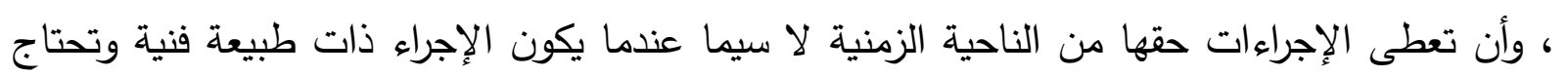

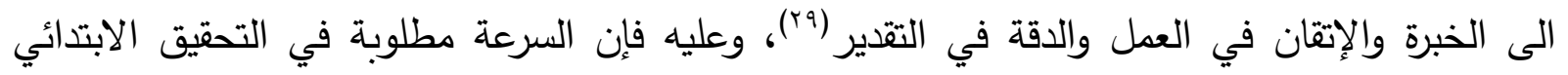

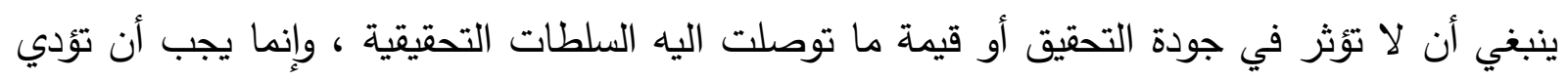


السرعة الى إنجاز المهام التحقيقية بصورة قانونية وكاملة دون إهمال أو مماطلة ، ومع ذلك فإن الأمر لا يخلو في مرحلة التحقيق الابتدائي من إمكانية تصور تحقق سبب لتأجيل التحقيق الابتدائي في الدعوى

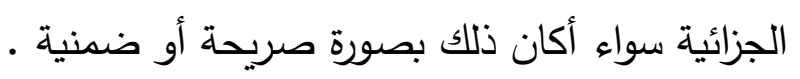

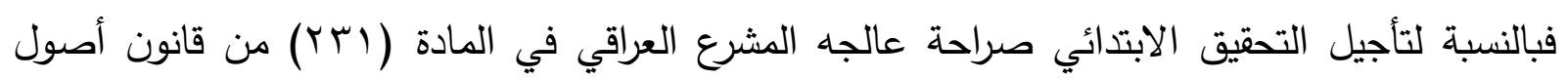
المحاكمات الجزائية في حالة عدم قدرة المتهم على الدفاع عن نفسه لإصابته بعاهة عقلية، والتي تم بيانها

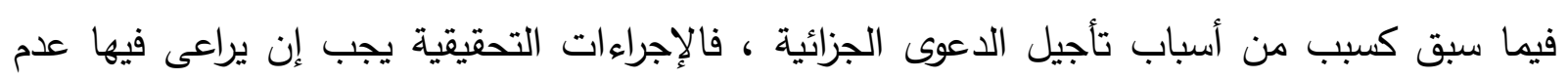

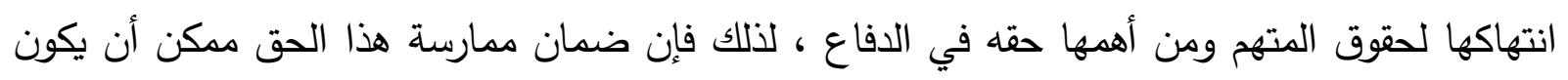

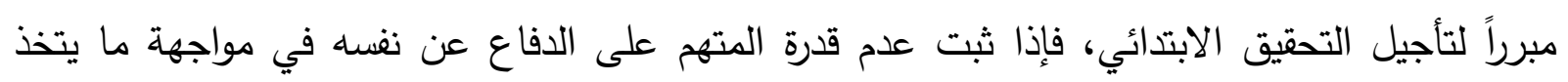

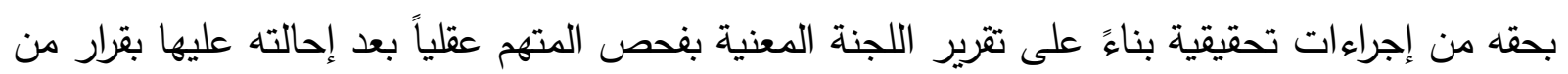

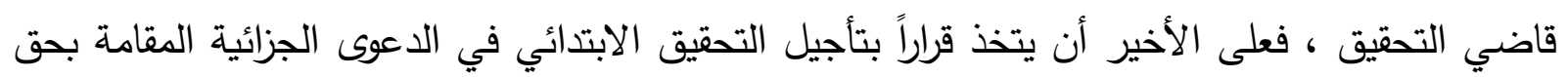

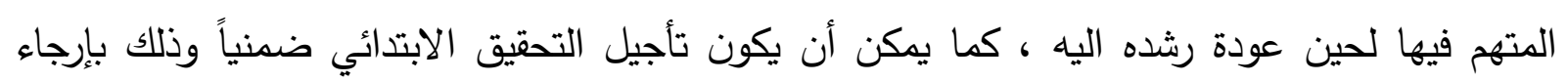

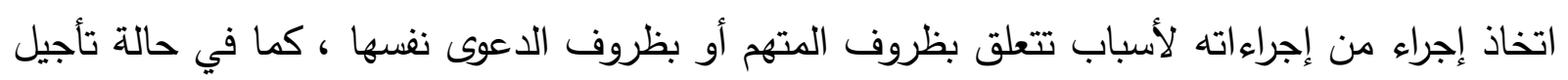

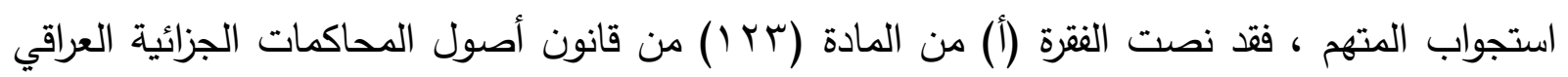
على أن " أ- على قاضي التحقيق أو المحقق أن يستجوب المتهم خلال اربع وعشرين ساعة من حضوره

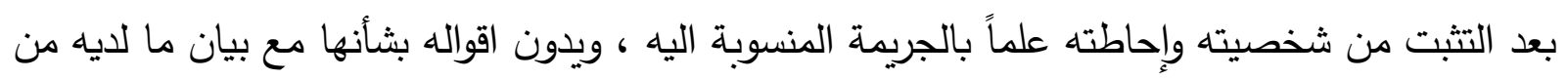

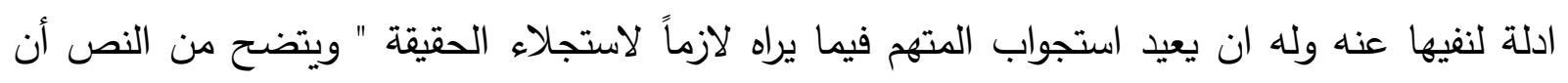

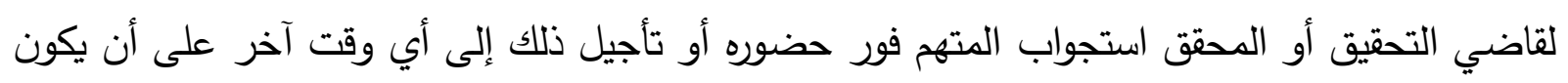
ذلك خلال أربع وعشرين ساعة، كما نصت الفقرة (ب)(·r)من المادة ذاتها على أن " قبل إجراء التحقيق مع المتهم يجب على قاضي التحقيق إعلام المتهم ما يلي : .... ثانياً: أن يكون له الحق في أن يتم

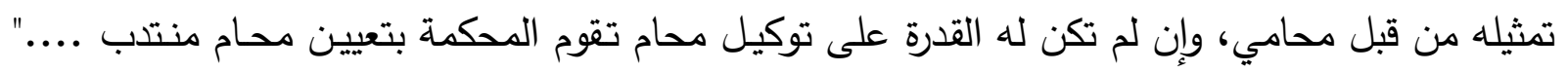
(ا؟ّ) ونصت الفقرة (ج) على أن "على قاضي التحقيق أو المحقق حسم موضوع رغبة المتهم في توكيل 
محام قبل المباشرة بالتحقيق ، وفي حالة اختيار المتهم توكيل محامي فليس لقاضي التحقيق أو المحقق

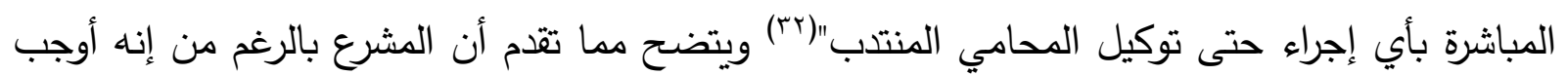

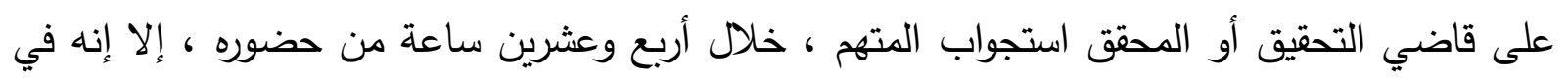
الوقت ذاته أوجب عدم المباشرة بأي إجراء إلا بعد تلبية رغبة المتهم في ممارسة حقه في أن يتم تمشيله

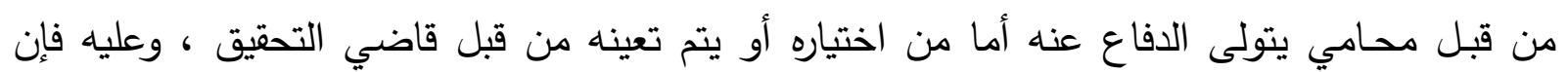
تأجيل جلسة الاستجواب لحين حصول التوكيل أمر وارد ، ويجب على قاضي التحقيق أو المحقق تأجيلها

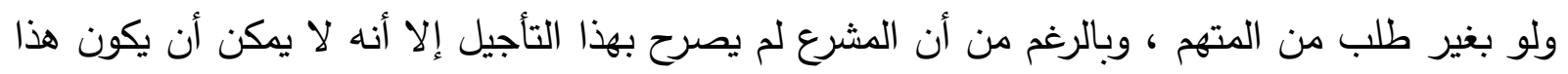

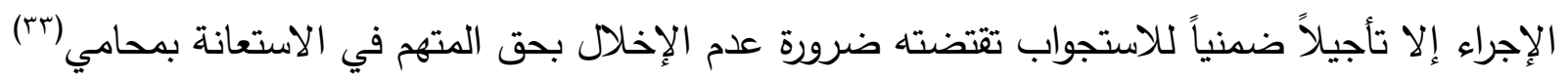

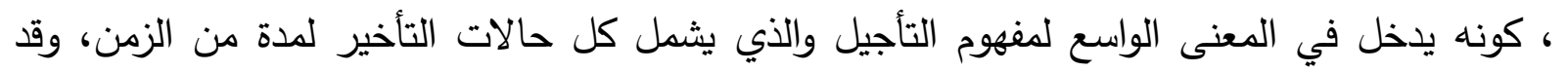
يستغرق ذلك مدة تزيد على أربع وعشرين ساعة ، إذ إن صيغة الإلزام بعدم مباشرة أي إجراء قبل توكيل

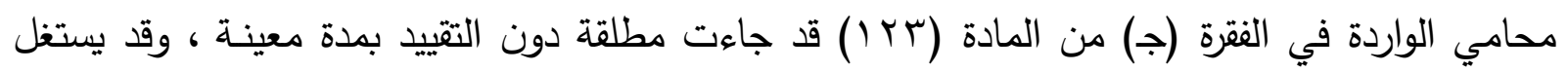
المتهم ذلك ويماطل في مسألة توكيل المحامي مما يؤدي الى عرقلة سير الإجراءات التحقيقية وتأخيرها ،

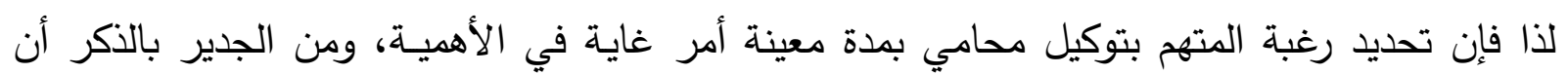

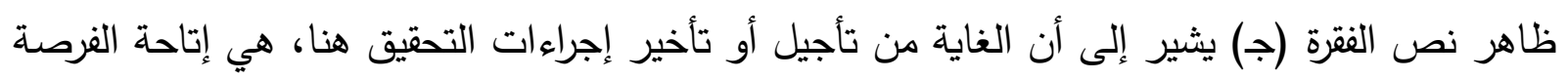

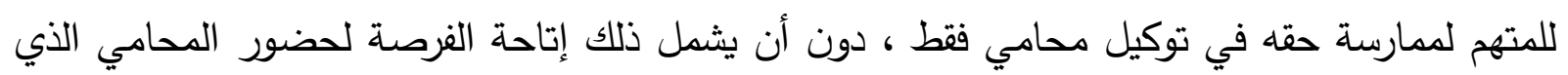

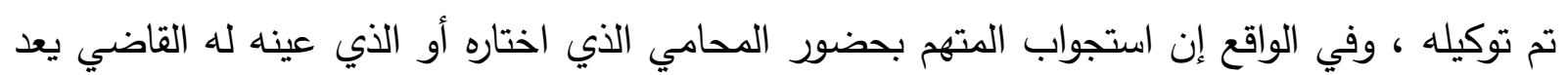

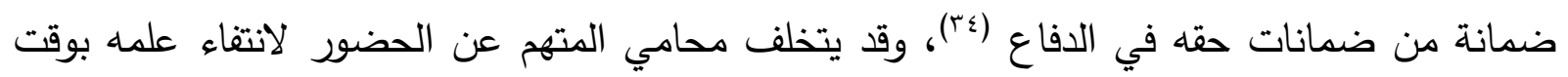
الاستجواب ، وعليه نقترح إعادة صياغة الفقرة (ج) بحيث تتضمن عدم جواز المباشرة باستجواب المتهم

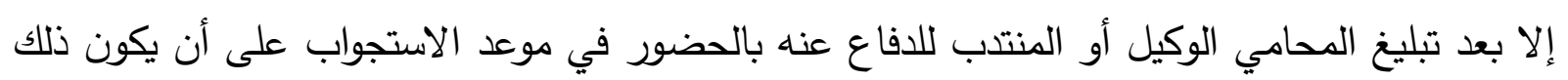

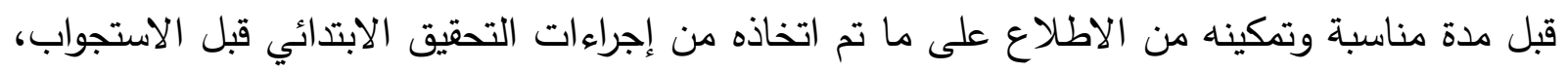

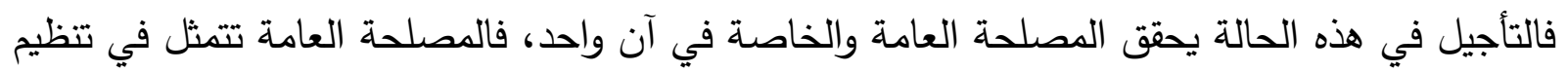


سير التحقيق الابتدائي وضمان سرعة إنجازه وعدم المماطلة فيه ، و المصلحة الخاصة تتمثل بحماية حق

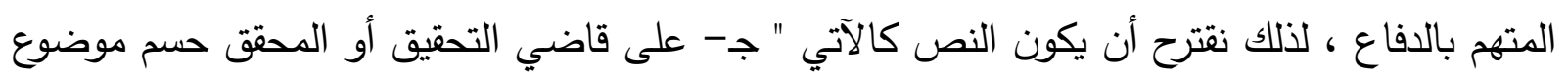
رغبة المتهم في توكيل محام قبل المباشرة بالتحقيق ، وفي حالة اختيار المتهم توكيل محامي فليس لقاضي التحقيق أو المحقق فى غير حالة التلبس وحالة الاستعجال بسبب الخوف من ضياع التياع الأدلة

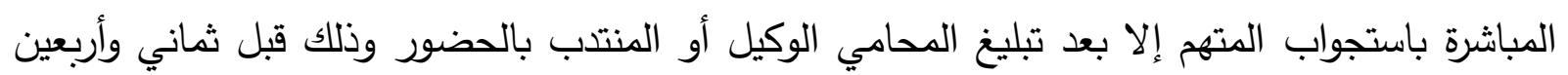

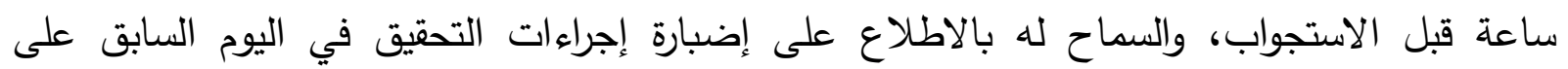
الاستجواب مالم يقرر قاضي التحقيق غير ذلك". ومن المسائل الإجرائية الأخرى التي تحتم تأجيل التحقيق ضمناً لمدة من الزمن مما يؤثر سلباً على سرعة سير إجراءاته هي تأخر الجهات الرسمية ذات العلاقة في الإجابة على استفسارات قاضي التحقيق كتأخر

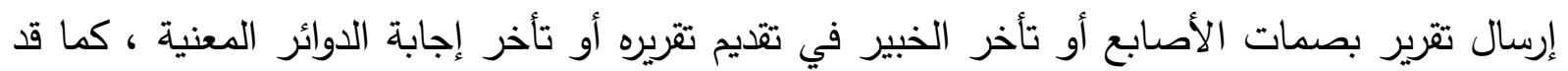

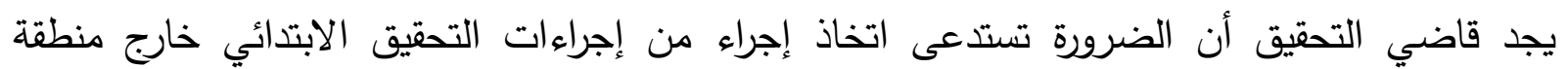
اختصاصه فينيب عنه قاضي التحقيق في تلك المنطقة للقيام بهذا الإجراء ، فقد نصت الفقرة (ب) من

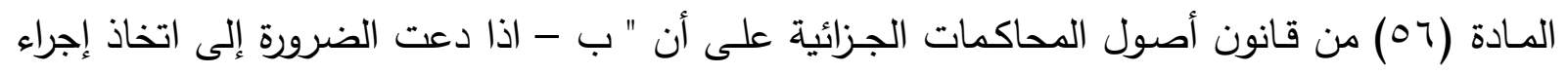
من إجراءات التحقيق خارج منطقة اختصاص القاضي فله أن ينيب عنه قاضي التحقيق في تلك المنطقة للقيام بهذا الإجراء ..."(ro) ، فيتضح من النص أن الإمر قد يتطلب تأخير التحقيق الابتدائي، من قبل فيل فئل قاضي التحقيق المنيب ، لمدة من الزمن لحين إتمام الإجراء التحقيقي المطلوب اتخاذه من قبل قاضي الإهي التحقيق المناب ، وهذا التأخير يدخل في المعنى الواسع للتأجيل . ومن الجدير بالذكر أن المشرع العراقي قد حدد سقف زمني لإنجاز التحقيق الابتدائي في الدعوى الجزائية

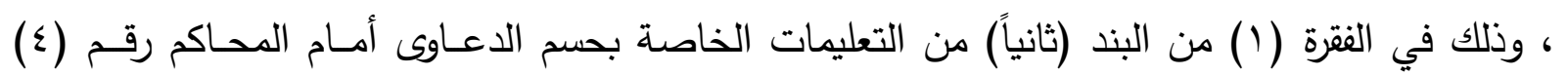

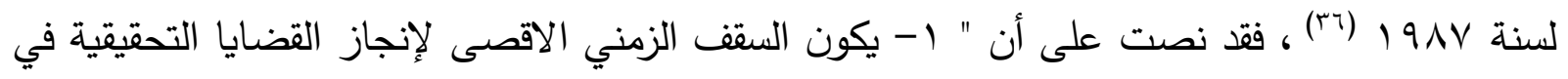

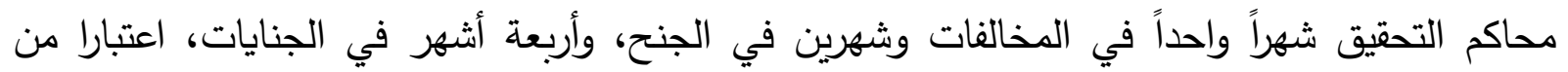


تاريخ تسجيل الإخبار فيها..." وعدم حسم الدعاوى التحقيقية خلال السقف الزمني يتحقق فيه معنى

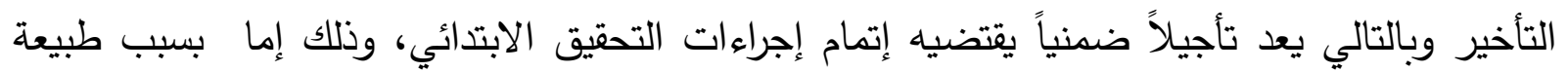

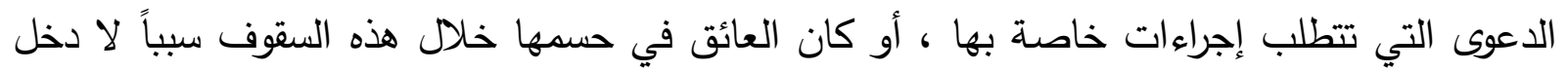

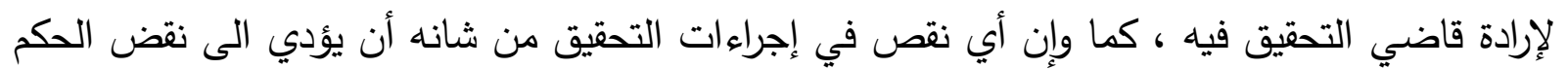
أو القرار الفاصل في الدعوى . أما بالنسبة لمرحلة المحاكمة وفيها يتحدد مصير المتهم فتقدير الأدلة فيها يكون نهائياً (rv) ، ولا يكون

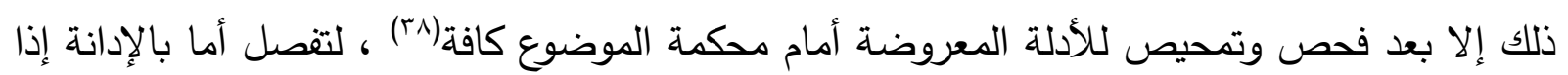

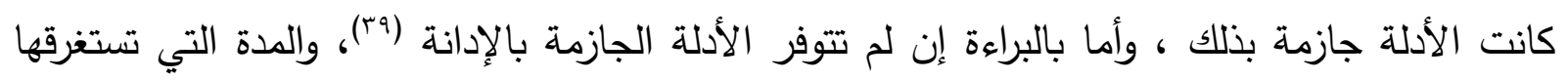

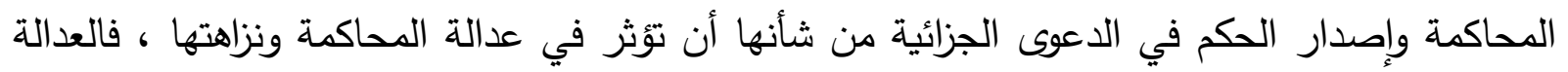

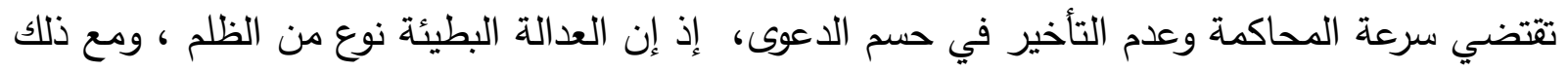

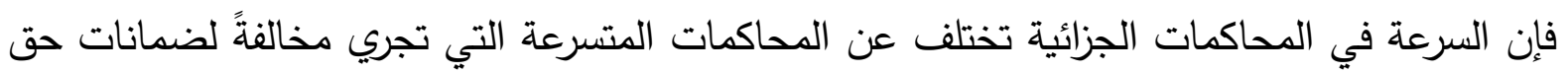

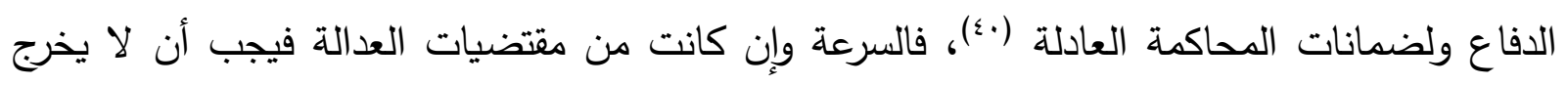
ذلك عن نطاق المعقولية فيكون على حساب العدالة نفسها ، وإجراءات المحاكمة متعددة ومتتوعة وتختلف

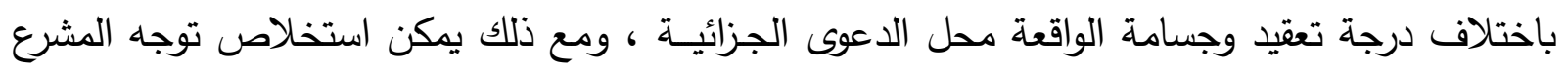
العراقي في قانون أصول المحاكمات الجزائية إلى وجوب الإسراع في إجراءات المحاكمة من خلال استقراء نصوصده دون أن يضع لذلك قاعدة محددة أو نص محدد يتضمن هذا التوجها، إلا أن إجراءات المحاكمة إنهاء

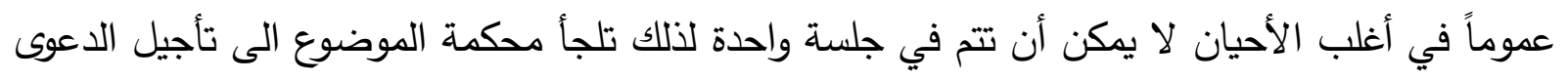
الجزائية لإنجاز مهمتها بصورة دقيقة بما يضمن حسن سير العدالة وعدم الإخـلال بحق الخصوم في لحي الدفاع، مما يحقق التوازن بين مصالح الخصوم المتعارضة في الدعوى الجزائية ، كما يحقق التوازن بين الإنين

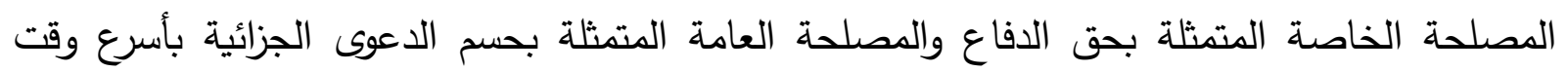
ممكن، فمرحلة المحاكمة أهم مرحلة في الدعوى الجزائية وللتأجيل فيها تطبيقاً واسعاً إذ تتحقق فيها أغلب ولبه 


\section{آثار تأجيل الدومى البرزائية في ضرى التشريعات البهزأيسة الإجرائية العربية}

أسبابـه ، على أن يكون التأجيل لأسباب جدية وحقيقيـة ، والتأجيل إجراء تتظيمي وهو بهذا الوصف

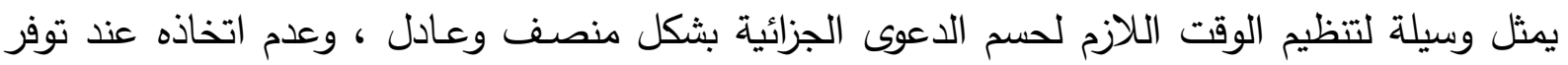
مسوغاته يوصم المحاكمة بالتسرع وعدم العدالة ، إلا أن الإفراط في اتخاذه - سواء بصورة تأجيلات

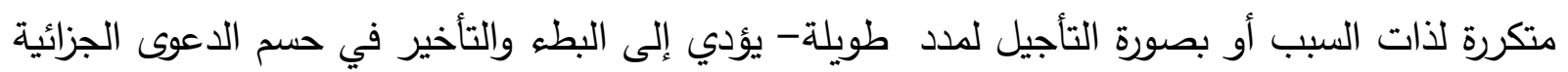

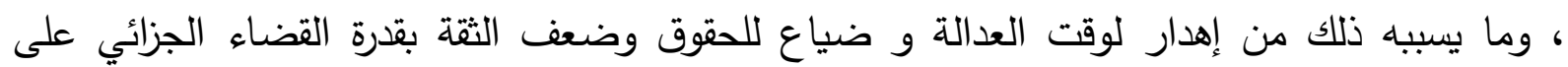
استحصالها ، وهذا ما يمثل الأثر السلبي للتأجيل على سرعة إجراءات الدعوى الجزائية متى استغرق حسم الدعوى الجزائية مدة طويلة تتجاوز حد المدة المعقولة ، ومن الجدير بالذكر أن المشرع العراقي حدد سقوفاً زمنية لحسم الدعوى الجزائية أمام محكمة الموضوع ، وتختلف هذه السقوف تبعاً لجسامة الجريمة فتكون

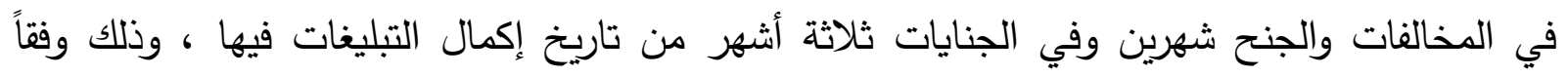

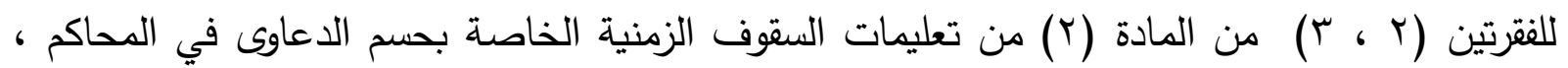
وحسم الدعاوى الجزائية خلال هذه السقوف الزمنية أمر وجوبي وليس جوازي ، فقد ألزم المشرع جميع المحاكم حسم الدعاوى التي تنظرها خلال السقوف الزمنية المحدة في هذه التعليمات ، الا اذا كانت طبيعة الدعوى تتطلب اجراءات خاصة بها أو كان العائق في حسمها خلال هذه السقوف سبباً لا دخل لإدارة المحكمة فيه، على ان تذكر المحكمة سبب تجاوز السقوف في محاضر الجلسات (1). المطلب الثاني: الأثر الإيجابي لتأجيل الدعوى الجزائية على سرعة إجراءاتها. على الرغم مما سبق بيانه من أثر سلبي لتأجيل الدعوى الجزائية على السرعة المطلوبة في اتخاذ وإنجاز

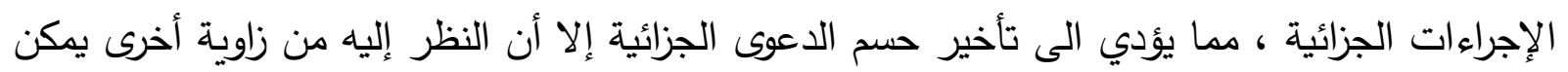

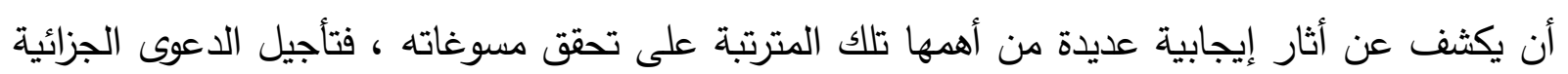
ضماناً لممارسة حق الدفاع من شأنه تحقيق المساواة بين الخصوم في تلك الدعوى، كما أن من آثار

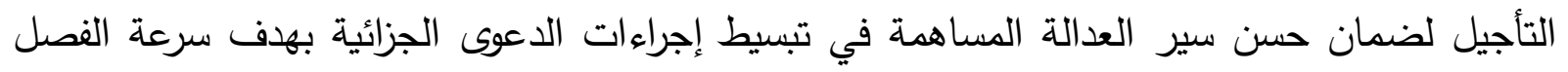
فيها ، ولا شك إن ذات الآثار من شأنها أن تترتب على التأجيل تحقيقاً للتوازن بين المصالح المتعارضة 
في الدعوى الجزائية، وقد سبق بيان ما يترتب على تأجيل الدعوى الجزائية من تحقيق للمساواة بين

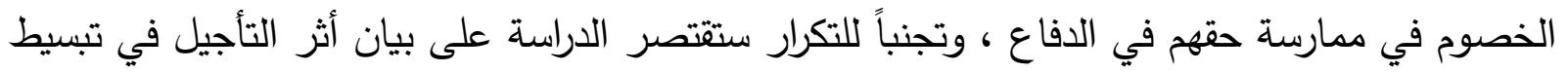

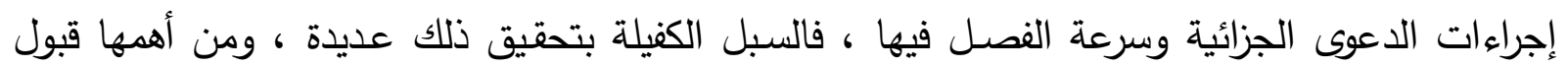
الصلح في جرائم معينة ، والتي لا تشكل خطورة بالغة على المجتمع فلا ضير عليه من قبول المصالحة فيها، كما أن من بين أسباب قبول الصلح في مثل هذه الجرائم هو إبعاد المتهم عن احتمالات تعرضها

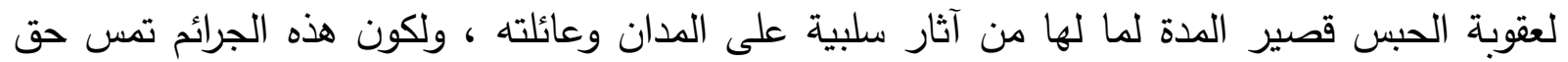

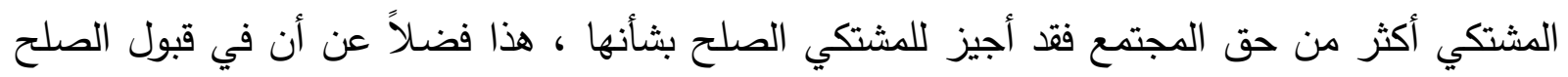

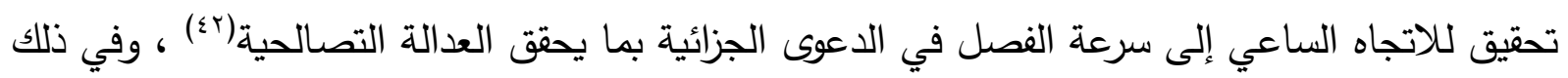
تعزيز لمصلحة المشتكي والمتهم وتحقيق التوازن بينهما ، وخفض لعدد الدعاوى المعروضة على المحاكم الجزائية ، مما يضمن حسن سير العدالة ، وقد أخذت التشريعات الجزائية الإجرائية محل الدراسة المقارنة بنظام الصلح في الدعاوي الجزائية المتعلقة بتلك الجرائم(r) ، وقد حدد المشرع العراقي الدعاوي المشمولة بإمكانية الصلح فيها بالدعاوى التي يتوقف تحريكها على شكوى المجني عليه أو من يقوم مقامه

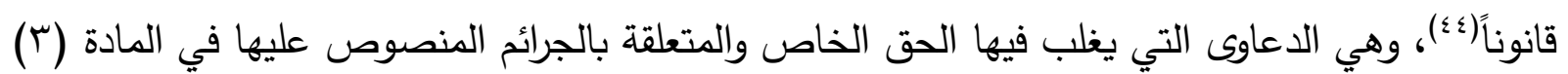
من قانون أصول المحاكمات الجزائية، وقبول المصالحة يجب البت فيه من دون الحاجة الى إصدار قرار بالإدانة ثم إصدار قرار بقبول الصلح، ففي ذلك إطالة لأمد الإجراءات لا مسوغ له قانوناً مادام القرار الصادر بقبول الصلح يعد بحكم القرار الصادر بالبراءة ، وهو يناقض الإدانة ولا يجوز اجتماع قرارين

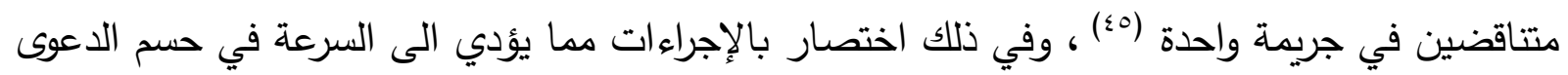

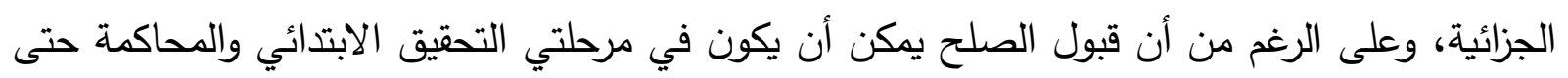

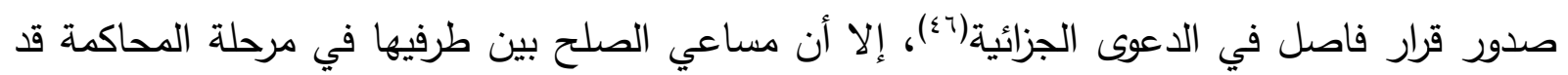

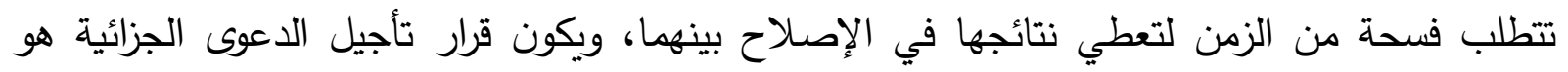

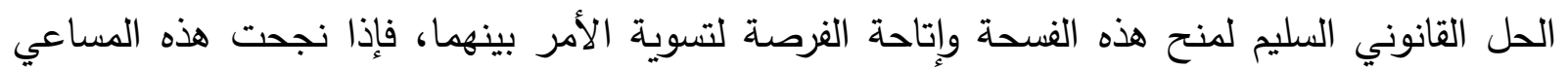


وطلب المجني عليه أو من يقوم مقامه الصلح مع المتهم تصدر محكمة الموضوع قراراً بقبول الصلح ،

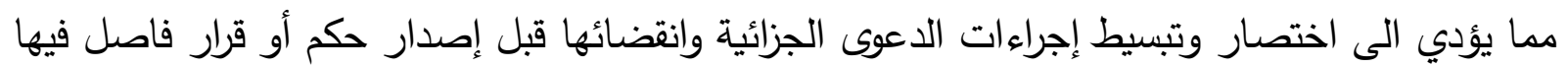
، وبذلك يكون لتأجيل الدعوى الجزائية دوراً إيجابياً في سرعة حسم الدعوى الجزائية لما له من أثر واضح في تيسير وقوع الصلح فيها . ويضاف الى ذلك أن تأجيل الدعوى الجزائية قد يؤدي إلى تعديل مسار سير الدعوى الجزائية بالثكل الذي

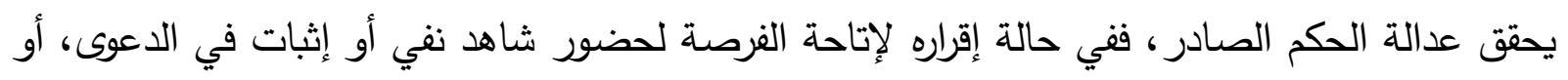
مفاتحة إحدى الجهات المختصة للاستفسار عن أمر جوهري في الاعوى، فإن ذلك قد يعدل من مسار

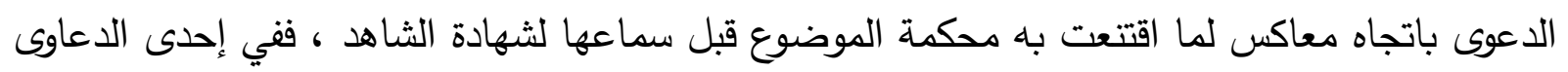
الجزائية طلب المتهم التأجيل لمفاتحة إدارة أحد السجون حيث كان مودع فيه لقضاء عقوبة سجن صادرة بحقه وذلك لإثبات تواجده داخل السجن في وقت ارتكاب الجريمة المتهم بارتكابها، وبالرغم من إن الدعوى الدئ الجزائية المقامة ضده كانت مهيأة للحكم بإدانته إلا أن محكمة الموضوع استجابت لطلبه وقد أكدت إدابت إدارة السجن بأنه في كان نزيلا متواجد في السجن في ذلك الوقت مما أدى إلى تعديل مسار الدعوى والحكم

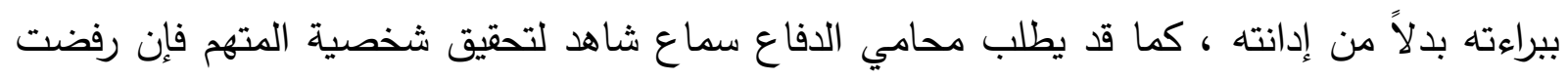

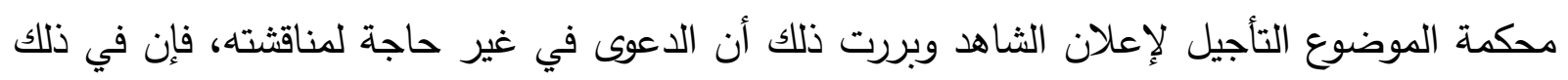

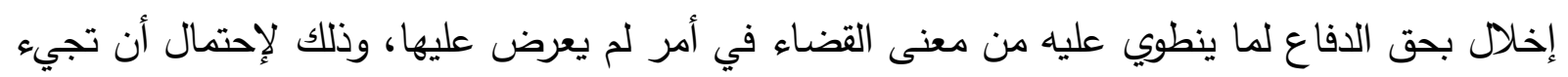

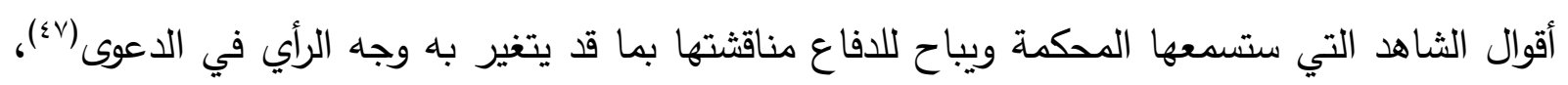

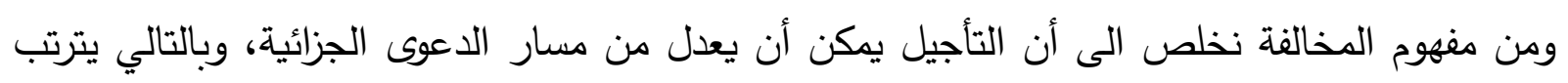
على التأجيل أثر إيجابي في حسم الدعوى الجزائية بحكم عادل ومنصف، وكذلك الحال بالنسبة للتأجيل لحضور الخبير القضائي الذي يكون لرأيه أثر واضح في إنتي إنيجة الدعوى . 
الخاتمة:

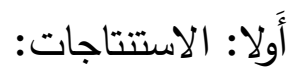

1- إن تأجيل الدعوى الجزائية إجراء قضائي يتخذ بقرار مسبب من جهة قضائية مختصة من تلقاء نفسها أو بناءً على طلب من أحد الخصوم أو من يمثله لتعطيل السير في الدعوى الجزائية إلى ميعاد لاحق يؤخر نظر الدعوى لحين حلوله. ץ- يترتب على تأجيل الدعوى الجزائية آثار متتوعة ومتشعبة تتصرف الى الى الدعوى الجزائية ذاتها أو

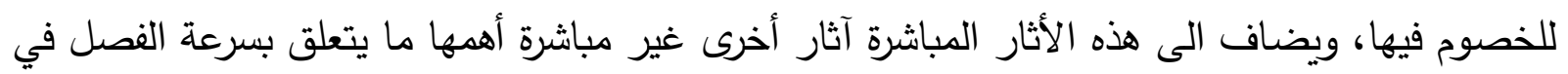

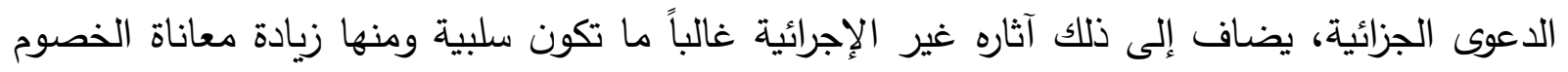
لما يترتب عليه من هدر للوقت وزيادة لنفقات الدعوى المبذولة من قبل الخصوم ، وذلك بسبب إطالة

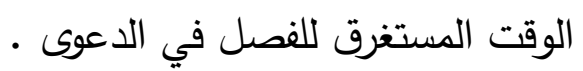
r- لتأجيل الدعوى الجزائية أثر إيجابي في إتاحة الفرصة لتهدئة النفوس وتقليل وتحجيم الاحقاد، تمهيداً لتحقق أثر آخر لله ذو طابع إجرائي يتجسد في سرعة حسم الاعوى الجزائية، وذلك بإتاحة الفرصة

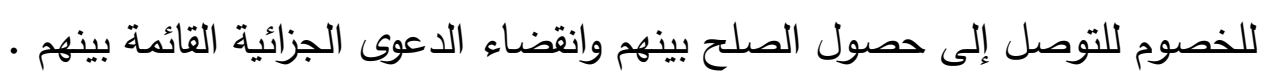

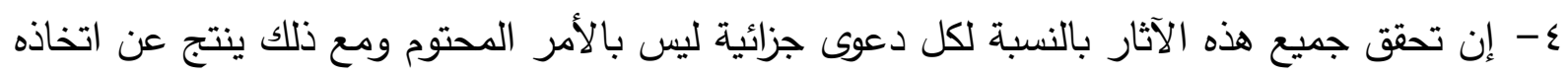
وجوب امتتاع الجهة القضائية التي قضت بالتأجيل عن النظر في الدعوى الجزائية خلال مدة التأجيل،

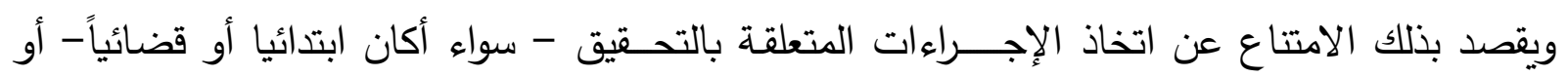
المحاكمة خلال مدة التأجيل. ثانياً: المقترحات: 1- نقترح على المشرع العراقي إعادة صياغة الفقرة (ج) بحيث يكون النص كالآتي "ج- على قاضي التحقيق أو المحقق حسم موضوع رغبة المتهم في توكيل محام قبل المباشرة بالتحقيق، وفي حالة اختيار

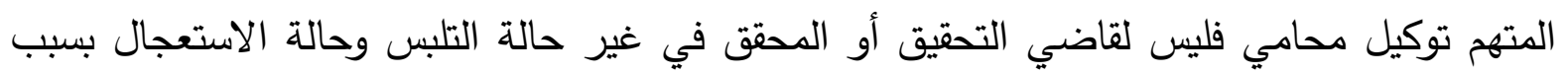


الخوف من ضياع الأدلة المباشرة باستجواب المتهم إلا بعد تبليغ المحامي الوكيل أو المنتدب بالحضور

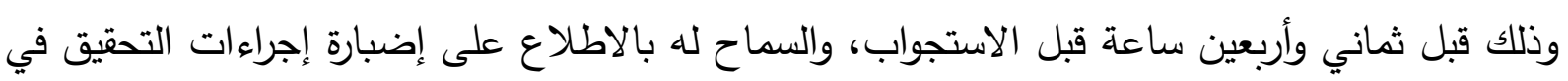

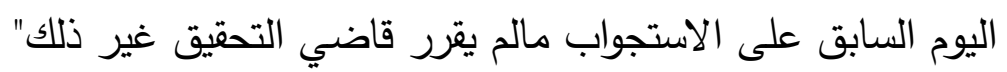
r- نقترح تفعيل العمل بالاعمامات الصادرة من هيأة الإشراف القضائي ومجلس القضاء التضاء الأعلى قبل

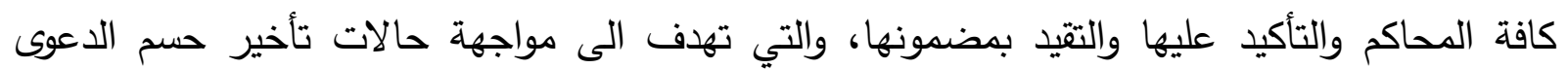
الجزائية والتخفيف من آثار تأجيل البت فيها.

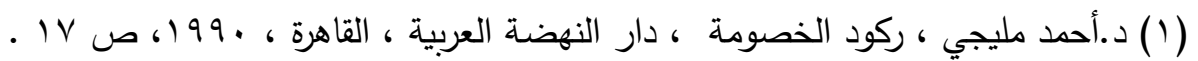

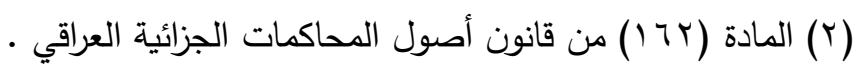

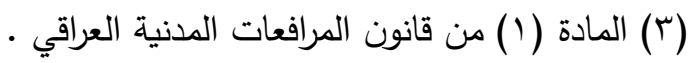

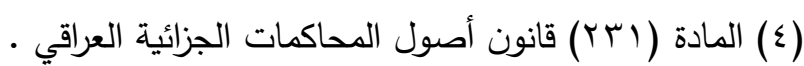

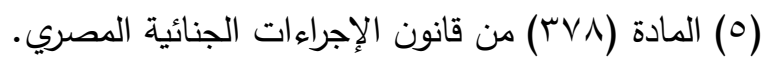

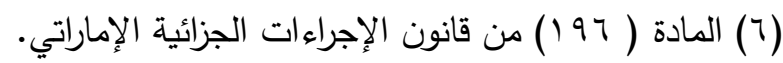

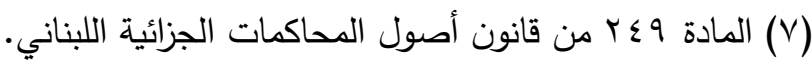

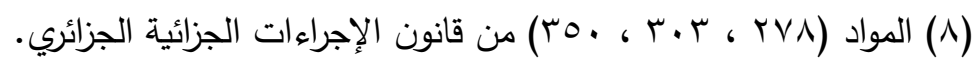

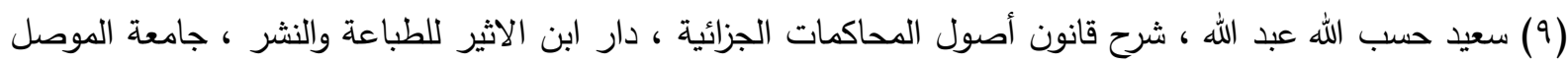
(

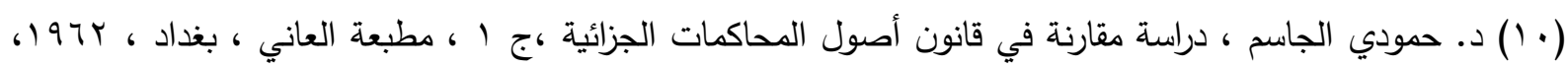
ص ص ص

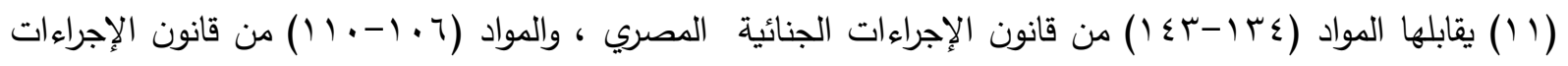

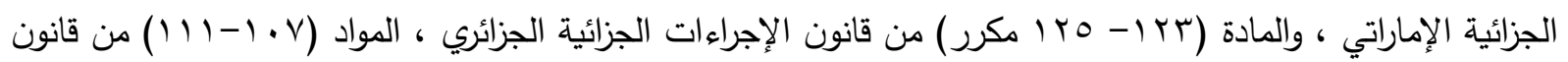

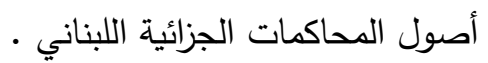




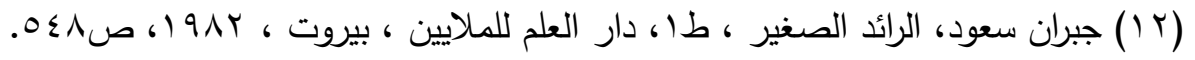

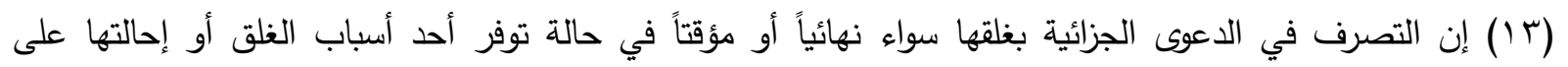

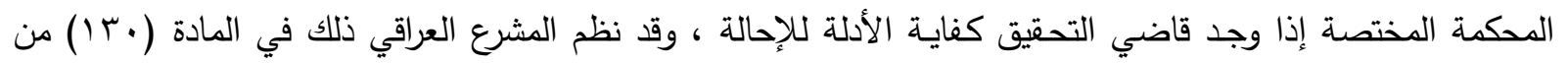

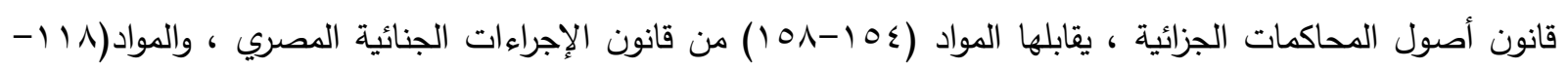

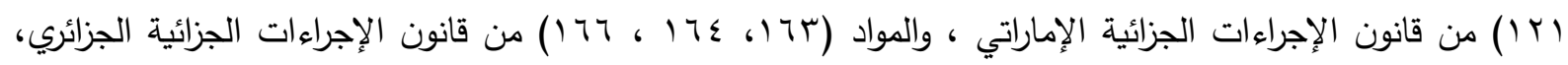

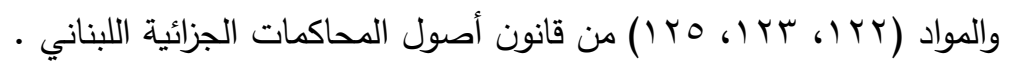

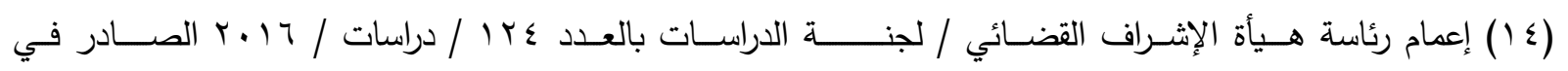
$. T \cdot 17 / 9 / T V$

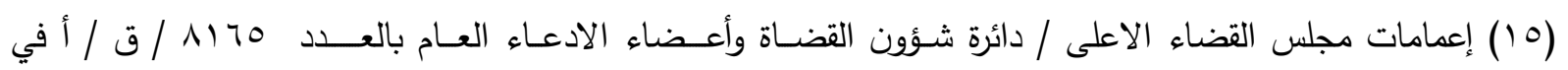
$. r \cdot 1 r / 9 / r$

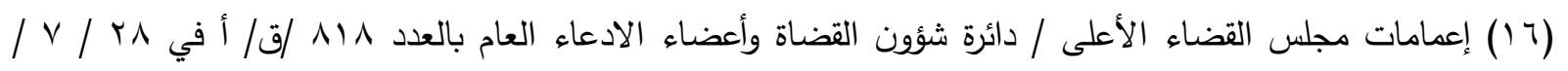
$.4 \cdot 17$

(V) سالم الثيباني ، الحماية الجنائية للحق في أصل قرينة البراءة دراسة مقارنه ، دار النهضة العربية ، القاهرة ،

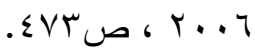

(1) (1) يقصد بمرحلة التحري وجمع الأدلة (مرحلة تمهيدية سابقة على مرحلة التحقيق الابتدائي تهدف الى جمع المعلومات

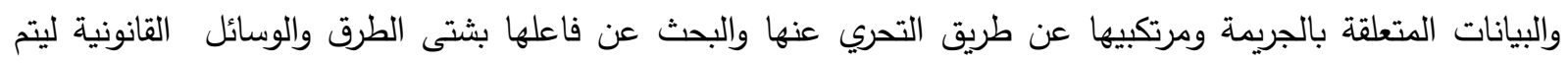

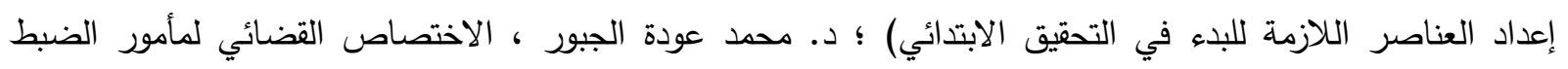

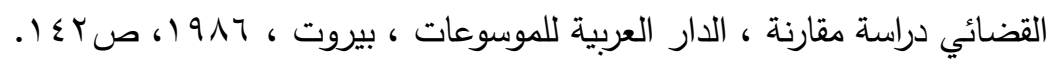

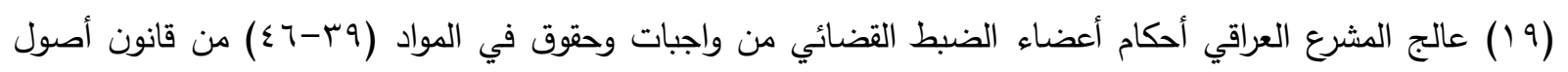

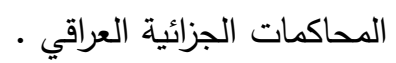

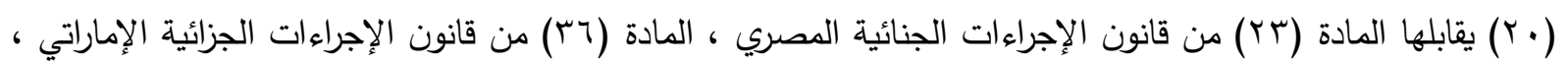

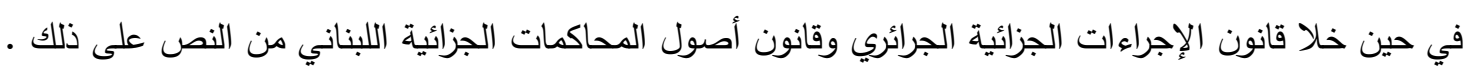




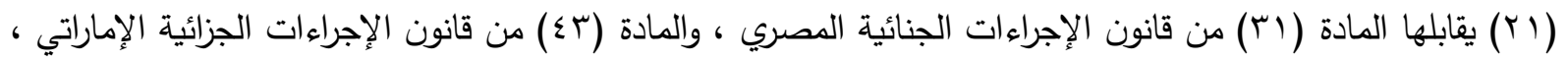

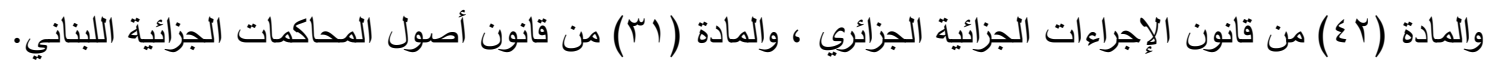

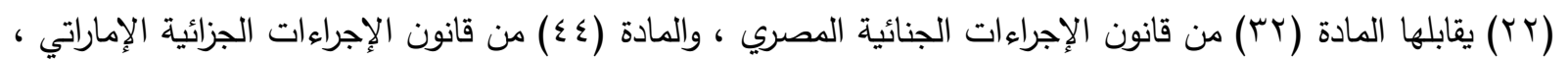

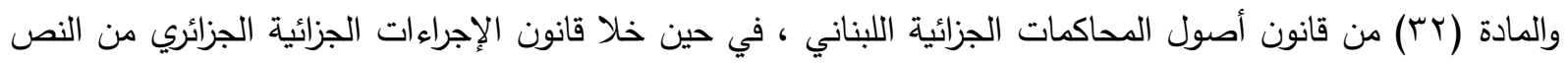
على ذلك .

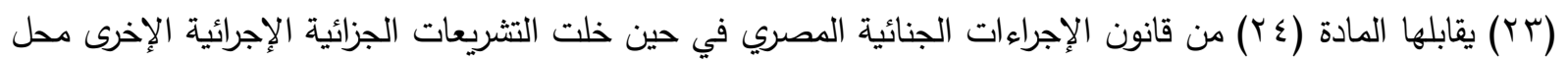
الدراسة من النص على ذلك ( (Y) علي السماك ، الموسوعة الجنائية للقضاء الجنائي العراقي ، الجزء الأول ، مطبعة الجاحظ ، بغداد ، .199 ، صע

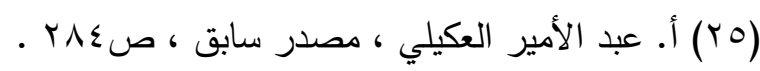

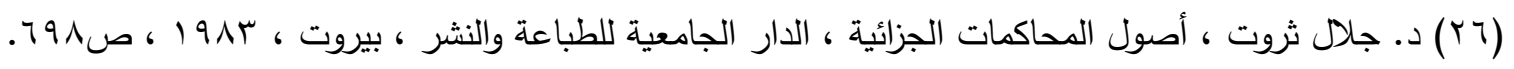

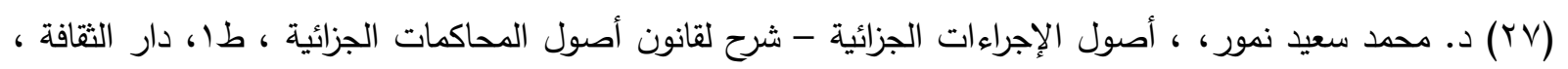

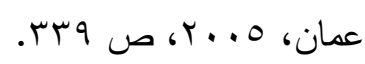

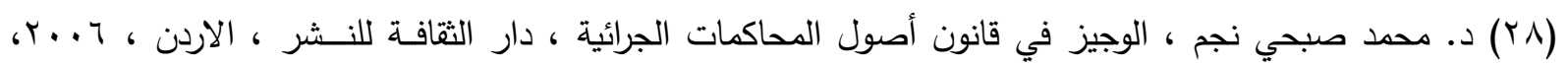
ص ص ص r

(Y (Y) يوسف مصطفى رسول ، المدد القانونية في الدعوى الجزائية دراسة تحليلية مقارنة ، دار الفكر العربي ، القاهرة ،

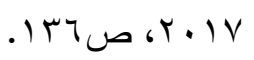

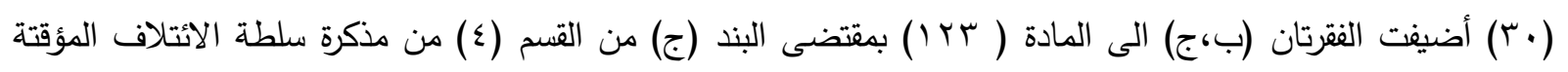
المنحلة رقم ب لسنة r . . r.

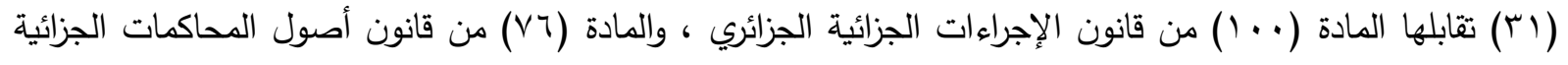

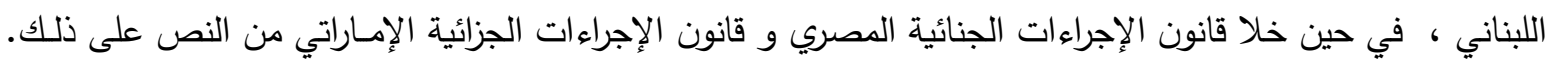




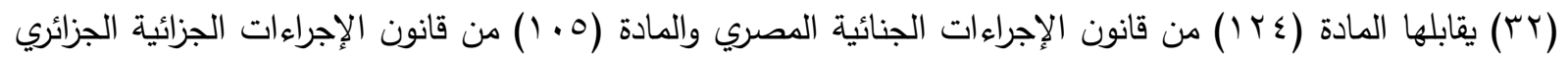

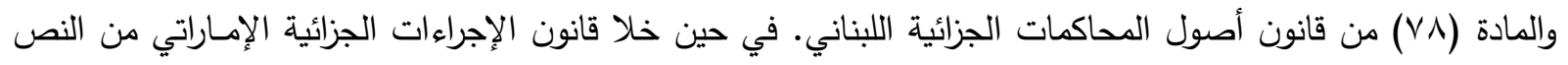
على ذلك . مالك

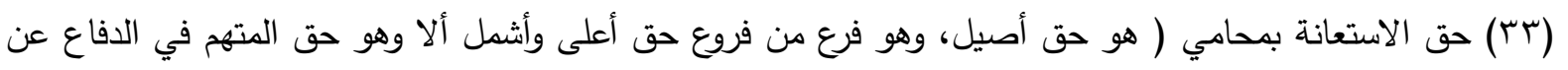

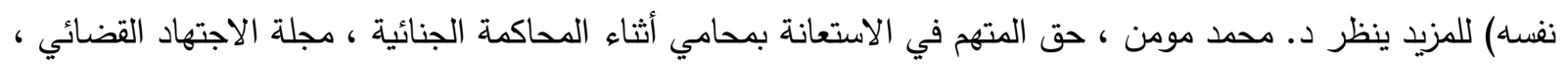

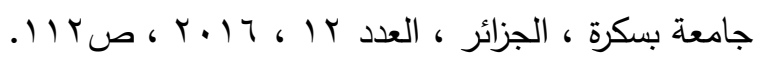

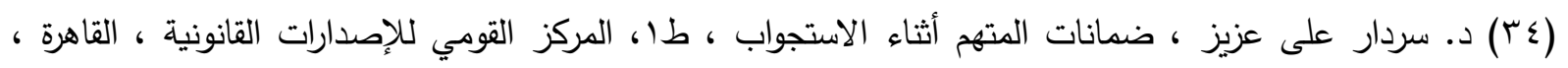

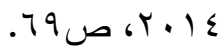

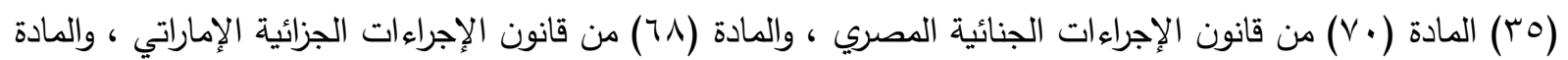

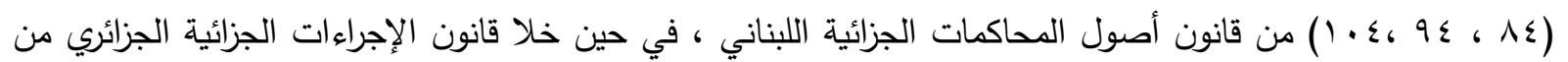

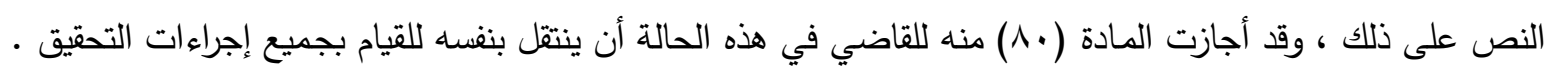

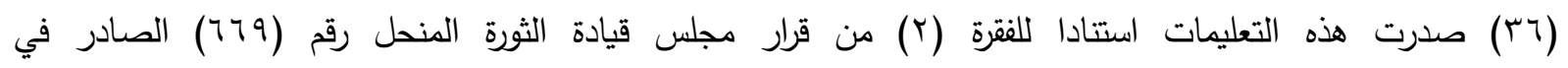
$.19 \Lambda \mathrm{V} / \mathrm{M} / \mathrm{K}$

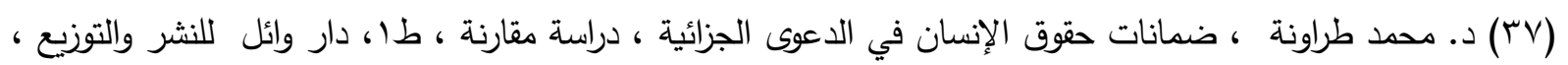

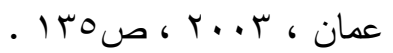

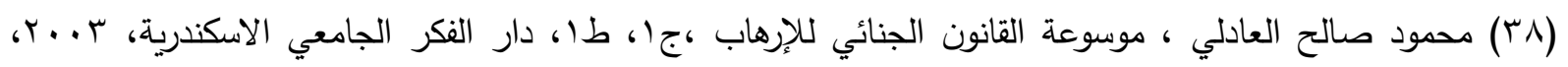
ص ص

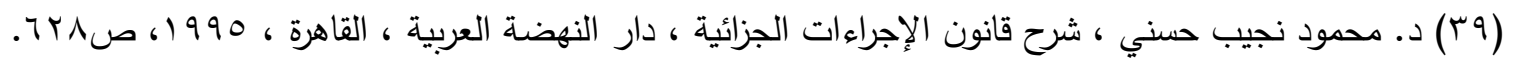

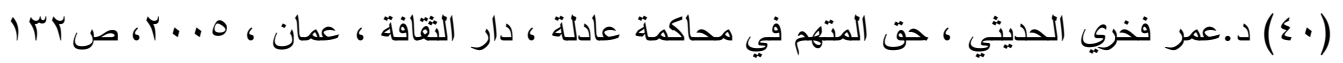

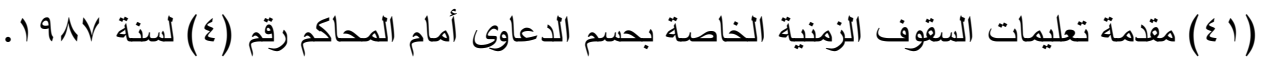

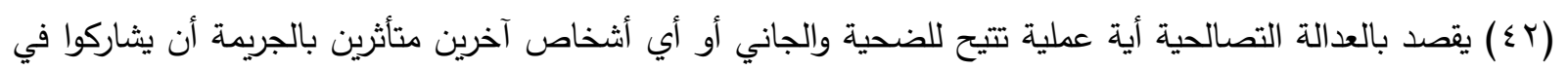
تسوية المسائل الناشئة عن تلك الجريمة ؛ هامل لفته العجيلي ، حق السرعة في الإجراءات الجزائية ، منشورات الحلبي

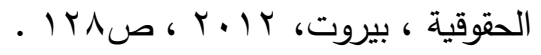




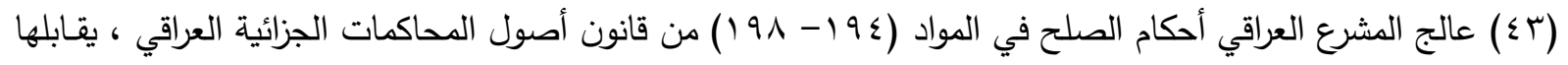
المـادتين (1/-1/ مكرر) من قانون الإجراءات الجنائية المصري ، في حين خلا قانون الإجراءات الجزائية الإماراتي من

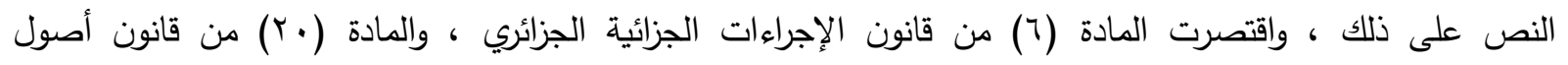
المحاكمات الجزائية اللبناني على بيان أثر الصلح في انقضاء الدعوى الجزائية . • ( (\$ § ) د. براء منذر كمال عبد اللطيف وبهاء الدين عطية عبد الكريم وأبو عبيدة منذر كمال عبد اللطيف ، السبل الكفيلة

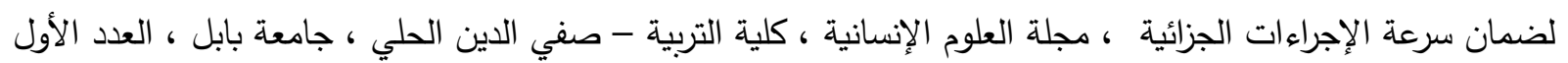
. 910 , r. IV ، •

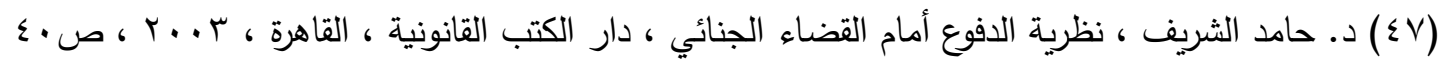
المراجح:

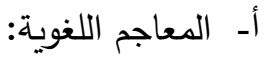
1-جبران سعود، الرائد الصغير ، طاه دار العلم للملايين ، بيروت ، ب19 أ. ب- الكتب القانونية

1- أحمد مليجي ، ركود الخصومة ، دار النهضة العربية ، القاهرة ، . 199 199

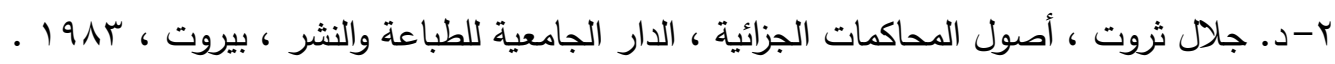

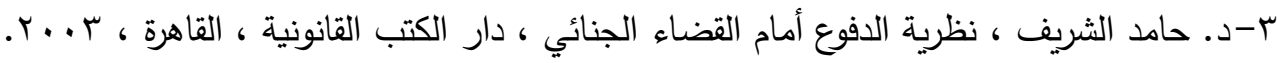

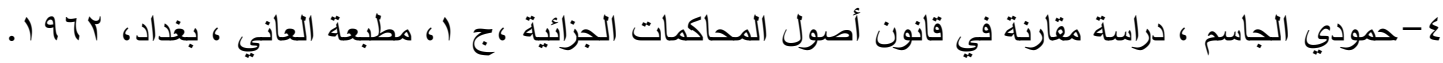
ه-سـالم الشيياني ، الحماية الجنائية للحق في أصل قرينة البراءة دراسة مقارنه ، دار النهضة العربية، القاهرة ، 7 ـ . ب. צ-د. سردار على عزيز ، ضمانات المتهم أثناء الاستجواب ، طا، المركز القومي للإصدارات القانونية، القاهرة ، .$r .1 \varepsilon$ V-سعيد حسب الله عبد الله ، شرح قانون أصول المحاكمات الجزائية ، دار ابن الاثير للطباعة والنشر ، جامعة الموصل ،

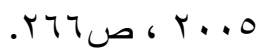


^-أ. عبد الامير العكيلي ود. سليم إبراهيم حربة ، شرح قانون أصول المحاكمات الجزائية ، طا ، المكتبة القانونية ،

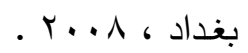

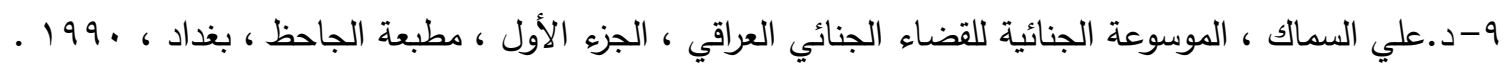

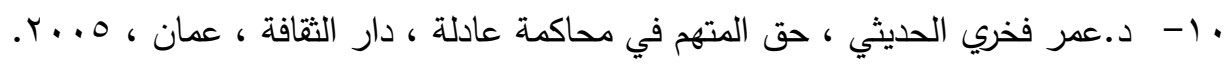

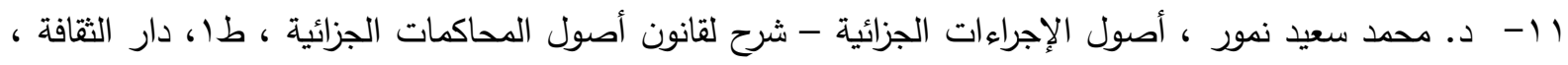
عمان ، r...

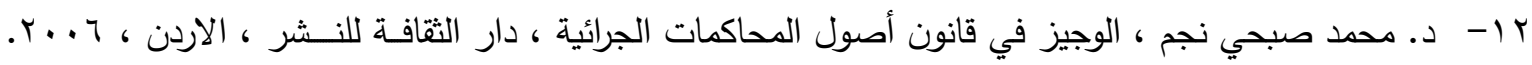

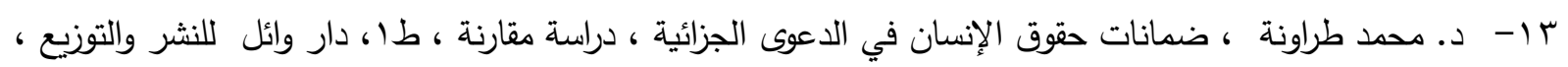

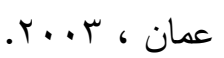

ع ا- - د. محمد عودة الجبور ، الاختصاص القضائي لمأمور الضبط القضائي دراسة مقارنة ، الدار العربية للموسوعات

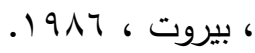

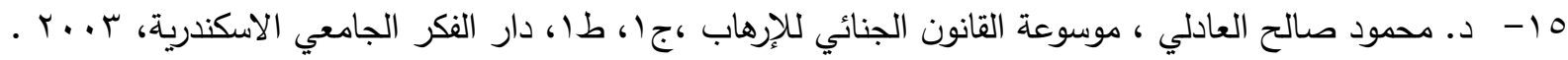

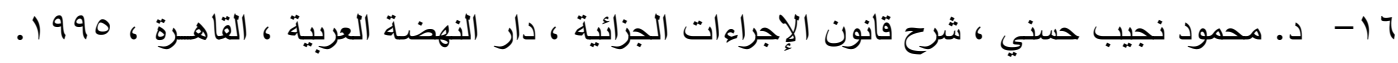

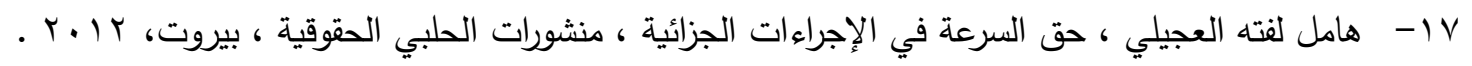

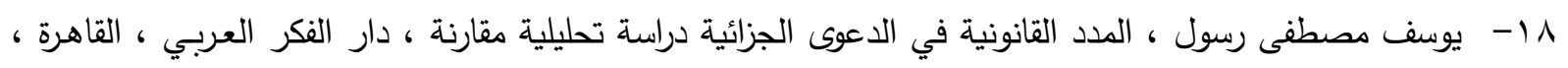
. r.IV ت- البحوث:

1-د. براء منذر كمال عبد اللطيف وبهاء الدين عطية عبد الكريم وأبو عبيدة منذر كمال عبد اللطيف ، السبل الكفيلة

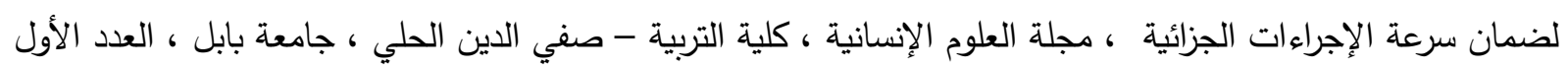
. r.IV 。

، ب-د. محمد مومن ، حق الدتهم في الاستعانة بمحامي أثناء الدحاكمة الجنائية ، مجلة الاجتهاد القضائي ، جامعة بسكرة

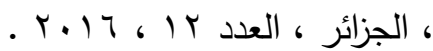
ث- القوانين والتعليمات: 
1- قانون الاجراءات الجنائية الدصري رقم (10.) لسنة .190 المعدل .

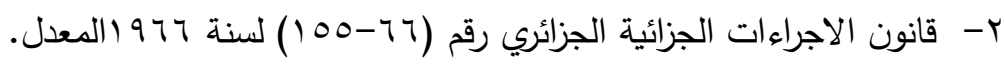

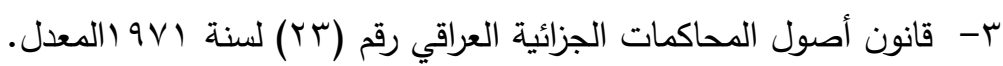

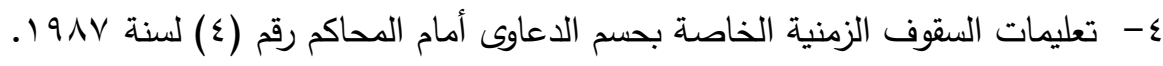

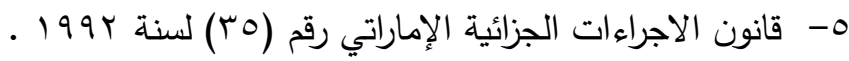

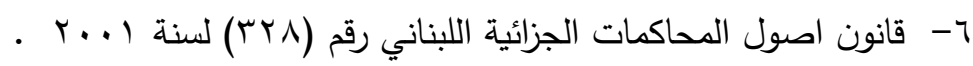

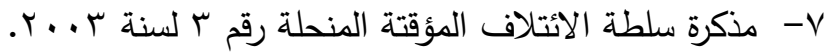

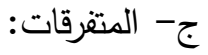

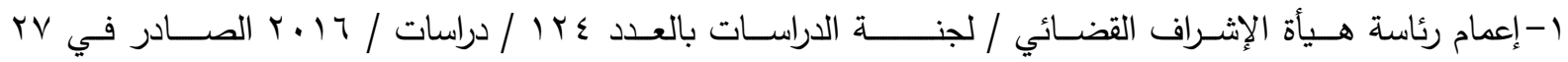
. r. $17 / 9 /$

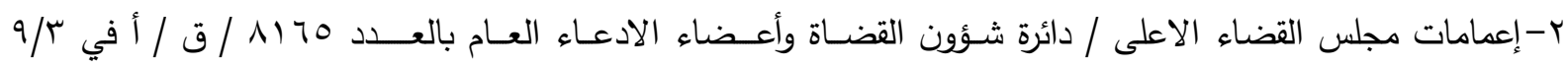
$. r \cdot \mid r /$

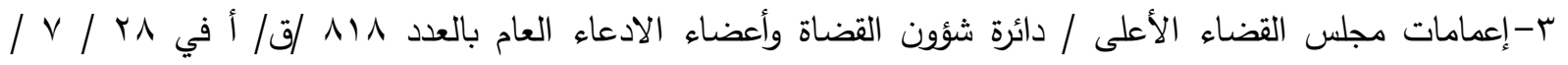
.$r \cdot 17$ 
